\title{
General and Localized Corrosion of the Drip Shield
}

J.C. Farmer, J.C. Estill, R.D. McCright

\section{August 20, 1999}

\section{Lawrence}

Livermore

National

Laboratory

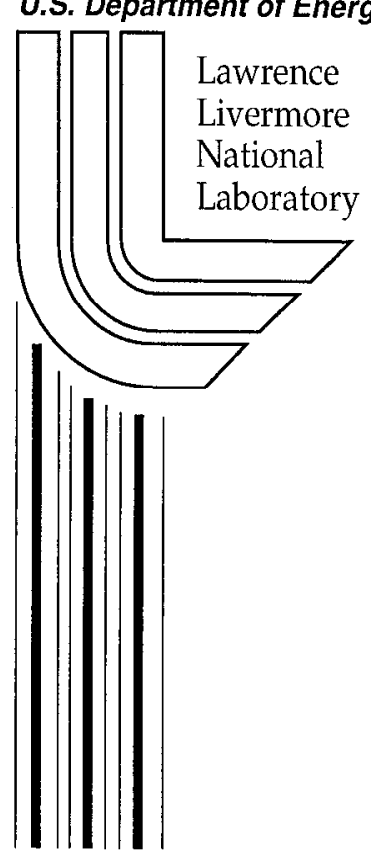




\section{DISCLAIMER}

This document was prepared as an account of work sponsored by an agency of the United States Government. Neither the United States Government nor the University of California nor any of their employees, makes any warranty, express or implied, or assumes any legal liability or responsibility for the accuracy, completeness, or usefulness of any information, apparatus, product, or process disclosed, or represents that its use would not infringe privately owned rights. Reference herein to any specific commercial product, process, or service by trade name, trademark, manufacturer, or otherwise, does not necessarily constitute or imply its endorsement, recommendation, or favoring by the United States Government or the University of California. The views and opinions of authors expressed herein do not necessarily state or reflect those of the United States Government or the University of California, and shall not be used for advertising or product endorsement purposes.

Work performed under the auspices of the U. S. Department of Energy by the University of California Lawrence Livermore National Laboratory under Contract W-7405-Eng-48.

This report has been reproduced

directly from the best available copy.

Available to DOE and DOE contractors from the

Office of Scientific and Technical Information

P.O. Box 62, Oak Ridge, TN 37831

Prices available from (423) 576-8401

http://apollo.osti.gov/bridge/

Available to the public from the

National Technical Information Service

U.S. Department of Commerce

5285 Port Royal Rd.,

Springfield, VA 22161

http://www.ntis.gov/

$\mathrm{OR}$

Lawrence Livermore National Laboratory

Technical Information Department's Digital Library

http://www.llnl.gov/tid/Library.html 


\title{
General and Localized Corrosion of The Drip Shield
}

\author{
ANL-EBS-MD-000004, Rev. 00A \\ by \\ Joseph C. Farmer, John C. Estill, and R. Daniel McCright
}

August 1999

Lawrence Livermore National Laboratory Livermore, California 


\section{CONTENTS}

FIGURES vii

TABLES $\mathrm{x}$

ABBREVIATIONS AND ACRONYMS ............................................................................. xii

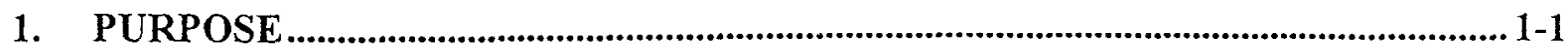

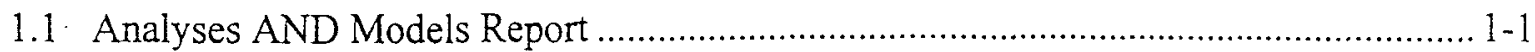

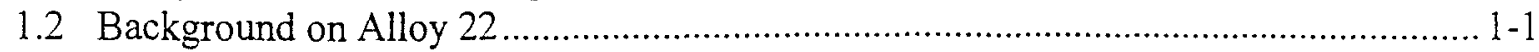

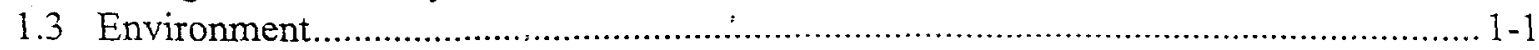

1.4 Relationship to Principal Factors ...................................................................... $1-2$

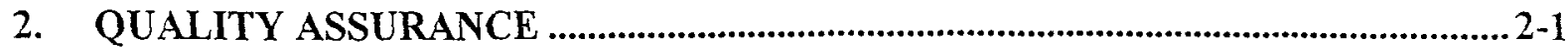

2.1 Procedure for Analyses and Models (AP-3.10Q) ..................................................... 2-1

2.2 Activity Plans (E-20-43/44, E-20-50, E-20-69, E-20-70 and E-20-81) ..................... 2-1

3. COMPUTER SOFTWARE AND MODEL USAGE ................................................. 3-1

3.1 Software Approved for QA Work......................................................................... 3-1

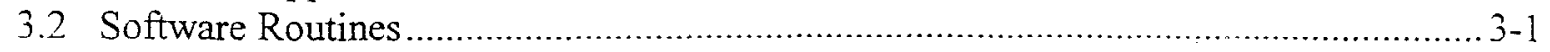

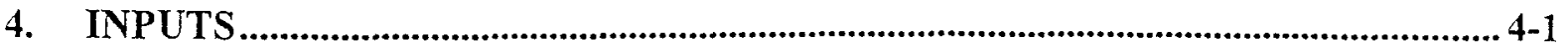

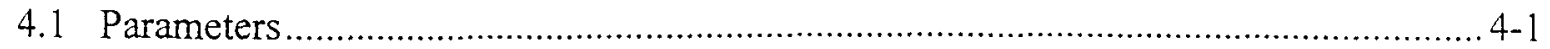

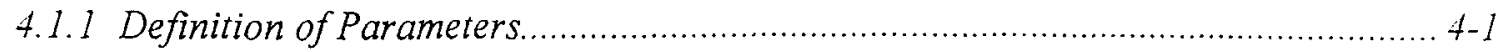

4.1.2 Determination of Input Parameters ................................................................... 4-2

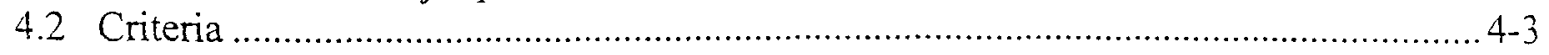

4.3 Codes and Standards ........................................................................................ 4-3

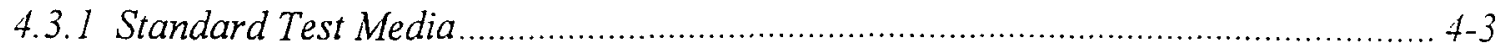

4.3.2 Cyclic Polarization Measurements ............................................................... 4-4

4.3.3 General Corrosion Measurments ….............................................................. 4-4

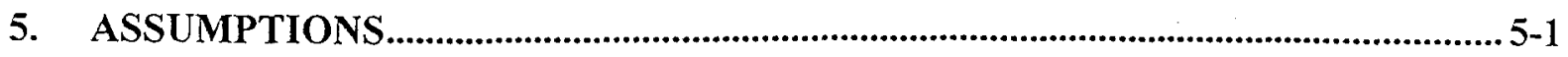

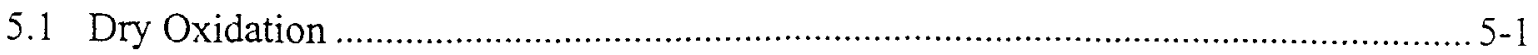

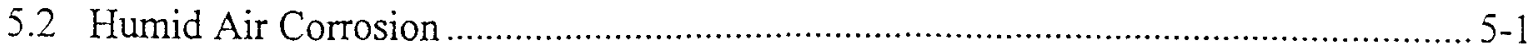

5.3 Aqueous Phase Corrosion ..................................................................................... 5-1

5.4 Dripping Condensate from Inner Surface of Drip Shield ........................................ 5-2

5.5 Flow Through Openings Between Drip Shields ....................................................... 5-2

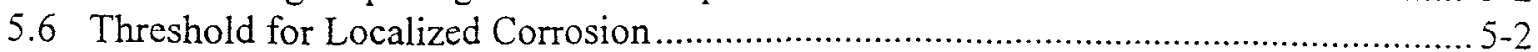

5.7 Effect of Gamma Radiolysis on Corrosion Potential ................................................... 5-2

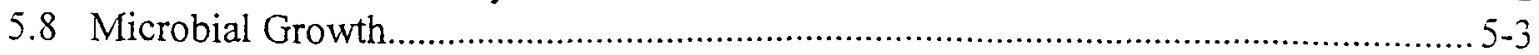

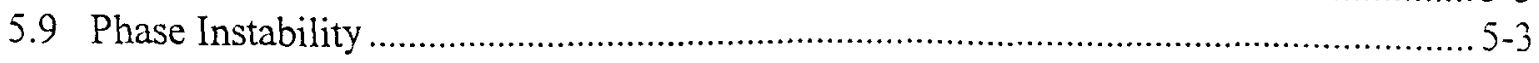

$\begin{array}{lll}\text { ANL-EBS-MD-000004, Rev.00A } & \mathrm{A} & \text { August 20, } 1999\end{array}$ 


\section{CHECK COPY}

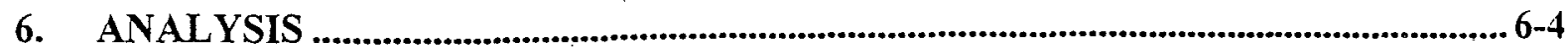

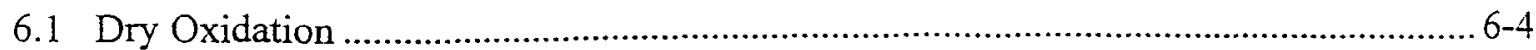

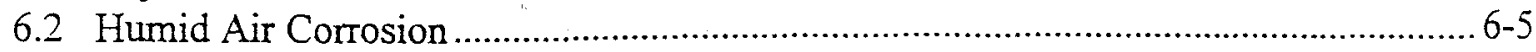

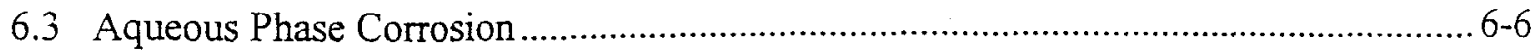

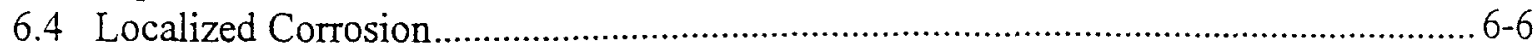

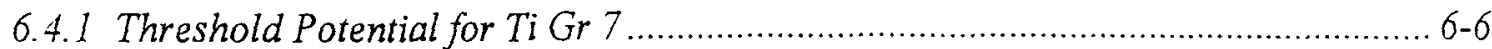

6.4 .2 Cyclic Polarization in Synthetic Concentrated J-13 Waters ................................. 6-6

6.4 .3 Correlation of Potential vs. Temperature Data for Various Test Media................. 6-7

6.4.4 Correction of Measured Potential for Junction Potential ................................... 6-13

6.5 Rates of General Aqueous-Phase Corrosion........................................................... 6-13

6.5.1 Corrosion Rates Based Upon Electrochemical Measurements ............................ 6-14

6.5.2 Corrosion Rates Based Upon Weight Loss Measurements................................... 6-20

6.5.3 Uncertainty in Weight Loss Measurements ................................................... 6-24

6.5.4 Error Analysis for Weight Loss Measurements .............................................. 6-25

6.6 Dissolved Oxygen in the Long Term Corrosion Test Facility ................................... 6-31

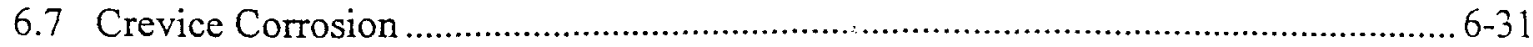

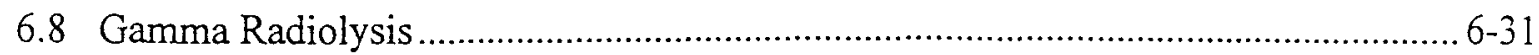

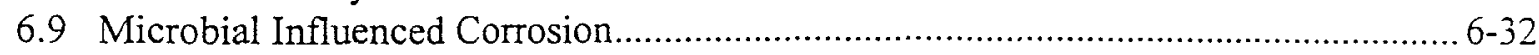

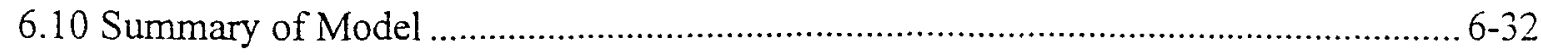

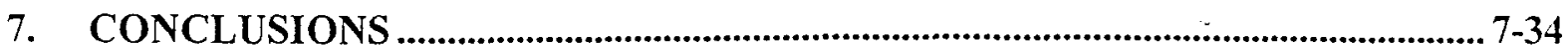

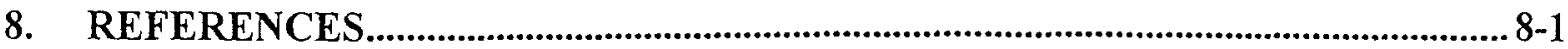

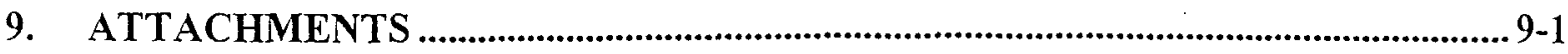

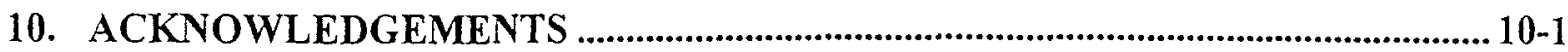




\section{CHECK COPY}

\section{FIGURES}

Page

Figure 6 - 1. Titanium Grade 7 in SSW at 120 Centigrade (NEA031s) [DTN \# ]................ 6-8

Figure 6 - 2. Titanium Grade 7 in SAW at 90 Centigrade (NEA025) [DTN \# ]................... 6-8

Figure 6 - 3. Titanium Grade 7 in SCW at 90 Centigrade (NEA029) [DTN \# ]................. 6-9

Figure 6 - 4. Titanium Grade 7 in SCW at 60 Centigrade (NEA019) [DTN \# ] ................... 6-9

Figure $6-5$. Titanium Grade 7 in SCW at 90 Centigrade (NEA003) [DTN \# ] .................6-10

Figure 6-6. Corrosion \& Threshold Potentials of Titanium Grade 7 in SSW (NEA03 1s) [DTN \# ].

Figure 6 - 7. Corrosion \& Threshold Potentials for Titanium Grade 7 in SAW [DTN \# ]...6-11

Figure 6 - 8. Corrosion \& Threshold Potentials for Titanium Grade 7 in SCW [DTN \# ].... 6-11

Figure 6 - 9. Corrosion \& Threshold Potentials for Titanium Grade 7 in SDW [DTN \# ]...6-12

Figure 6 - 10. Corrosion \& Passive Currents for Titanium Grade 7 in SSW [DTN \# ]......... 6-17

Figure 6 - 11. Corrosion \& Passive Currents for Titanium Grade 7 in SAW [DTN \#] ......... 6-17

Figure 6 - 12. Corrosion \& Passive Currents for Titanium Grade 7 in SCW [DTN \# ] ......... 6-18

Figure 6 - 13. Corrosion \& Passive Currents for Titanium Grade 7 in SDW [DTN \# ]......... 6-18

Figure 6 - 14. General Corrosion of Ti Gr 16, $6 \& 12$ Month Wt. Loss Samples from LTCTF, Percentile vs. Corrosion Rate [DTN \#].

Figure 6 - 15. General Corrosion of Ti Gr 16, $6 \& 12$ Month Crevice Samples from LTCTF, Percentile vs. Corrosion Rate [DTN \# ]

Figure 6 - 16. Schematic Representation of Corrosion Model for Drip Shield. $6-33$ 


\section{CHECK COPY}

\section{TABLES}

Page

Table 6 - 1. Summary of Correlated Corrosion and Threshold Potential Data [DTN \# ] .... 6-12 Table 6 - 2. Values of $E_{\text {corr }}$ and $E_{\text {critical }}$ Based on Correlated Cyclic Polarization Data [DTN \#]

Table 6 - 3. Summary of Junction Potential Corrections for Cyclic Polarization (Volts) [DTN $\#$ \#.

Table 6 - 4. Conversion of Current Density to Corrosion (Penetration) Rate [DTN \# ]...... 6-16

Table 6 - 5. Conversion of Current Density to Corrosion (Penetration) Rate [DTN \# ]...... 6-16

Table 6-6. Coefficients for Regression Equations Used to Represent Corrosion and Passive Current Data [DTN \# ] .......................................................................... 6-19

Table 6 - 7. Standard Areas Under Density Function for Normal Distribution ...................... 6-24

Table 6-8. Mean and Standard Deviation of General Corrosion Rates - Weight Loss ..... 6-24

Table 6 - 9. Mean and Standard Deviation of General Corrosion Rates - Crevice Samples 6-24

Table 6-10. Summary of Error Analysis for Corrosion Rates Based Upon Weight Loss Measurements

Table 6 - 11. Error Analysis for LTCTF Corrosion Rates - Definitions. .............................. 6-27

Table 6 - 12. Error Analysis for LTCTF Corrosion Rates - Assume Weight Loss of 0.0001 Grams. 6-28

Table 6 - 13. Error Analysis for LTCTF Corrosion Rates - Assume Weight Loss of 0.001 Grams.

Table 6 - 14. Error Analysis for LTCTF Corrosion Rates - Assume Weight Loss of 0.01 Grams

Table 6 - 15. Assumed Distribution of Localized Corrosion Rates for Alloy 22. 6-30

6-31 


\section{ABBREVIATIONS AND ACRONYMS}

AFM Atomic Force Microscope

AMR Analyses and Models Report

CP Cyclic Polarization

DOX Dry Oxidation

DS Drip Shield

DTN Data Tracking Number

EBS Engineered Barrier System

FW $\quad$ Formula Weight

GC General Corrosion

HAC Humid Air Corrosion

LC Localized Corrosion

I.I.NI. Lawrence Livermore National Laboratory

LTCTF Long Term Corrosion Test Facility

$\mathrm{M} \& \mathrm{O} \quad$ Management and Operating Contractor

NHE Normal Hydrogen Electrode

PMR Process Model Report

RH Relative Humidity

SCC Stress Corrosion Cracking

SCE Saturated Calomel Electrode

SAW Simulated Acidic Concentrated Water

SCW Simulated Concentrated Water

SDW Simulated Dilute Water 


$\begin{array}{ll}\text { SSW } & \text { Simulated Saturated Water } \\ \text { WF } & \text { Waste Form } \\ \text { WP } & \text { Waste Package } \\ \text { WPOB } & \text { Waste Package Outer Barrier } \\ \text { XRD } & \text { X-ray diffraction }\end{array}$




\section{CHECK COPY}

\section{PURPOSE}

\subsection{ANALYSES AND MODELS REPORT}

The purpose of the process-level model is to account for both general and localized corrosion of the Drip Shield (DS), which is assumed to be a titanium alloy. This model will include several sub-models, which will account for dry oxidation, humid air corrosion, general corrosion in the aqueous phase, and localized corrosion in the aqueous phase. This Analyses and Models Report (AMR) serves as a feed to the Waste Package Degradation Process Model Report (PMR) and Model Abstraction for WAPDEG.

\subsection{BACKGROUND ON ALLOY 22}

Titanium alloys are now being considered for construction of the DS. The current recommendation is to use Ti Gr 7 [UNS R52400; $0.03 \% \mathrm{~N}$ (max.), $0.10 \% \mathrm{C}$ (max.), $0.015 \% \mathrm{H}$ (max.), $0.25 \% \mathrm{O}$ (max.), $0.30 \%$ (max.) Fe, 0.12-0.25\% (max.) Pd, 0.1\% Residuals (max.), 0.4\% Residuals (total), and $\mathrm{Ti}$ (bal.)]. A similar material used in the testing program is $\mathrm{Ti}$ Gr 16, which has 0.04 to $0.08 \% \mathrm{Pd}$. These materials are reviewed elsewhere (Pasupathi 1999; Gdowski 1991). The unusual corrosion resistance of these titanium alloys is apparently due to the formation of a passive film of $\mathrm{TiO}_{2}$, which is stable over a relatively wide range of potential and $\mathrm{pH}$ (Pourbaix 1974). Corrosion tests of Ti Gr 16 have been conducted in the Project's Long Term Corrosion Test Facility (LTCTF) (Estill 1998). Test media used in this facility include Simulated Acidic Concentrated Water (SAW), which is about one-thousand times more concentrated than the ground water at Yucca Mountain ( $\mathrm{J}-13$ well water), and has been acidified to a $\mathrm{pH}$ of approximately 2.7 . The rates of general corrosion and oxidation of this material have been shown to be very low.

\subsection{ENVIRONMENT}

The DS will experience a wide range of conditions during its service life. Initially, the underlying high-level waste containers will be relatively hot. The DS surface may be kept dry by the heat generated from radioactive decay. However, the temperature will eventually drop to levels where both humid air and aqueous phase corrosion will be possible. Crevices will be formed between the DS and its support structure on the invert. Crevices may also form between the DS and mineral precipitates, corrosion products, dust, rocks, cement and biofilms. If the DS settles or collapses, crevices may even form with the WP. There has been concern that the crevice environment may be more severe than the near field environment (NFE). The hydrolysis of dissolved metal can lead to the accumulation of $\mathrm{H}^{+}$and a corresponding decrease in $\mathrm{pH}$. Fielddriven electromigration of various anions into the crevice must occur to balance cationic charge associated with $\mathrm{H}^{+}$ions (Gartland 1997; Walton et al. 1996; Shoesmith 1995). These exacerbated conditions can set the stage for subsequent attack of this corrosion resistant material (CRM) by passive corrosion, pitting (initiation \& propagation), hydrogen induced cracking (HIC), stress corrosion cracking (initiation \& propagation), or other mechanisms. 


\subsection{RELATIONSHIP TO PRINCIPAL FACTORS}

Degradation of the DS is key to understanding one of the most important principal factors in repository performance. This principal factor is the amount water transmitted through openings in the DS to the outer surface of the WP. This flux of water will ultimately determine the rate of release of radionuclides out. Once water contacts (touches) the surface of the WP, its fate becomes intertwined with that of the WP. The models and supporting experimental data to account for both DS and WP degradation, as well as the evolution of water involved in the various degradation processes, have been developed by Waste Package Operations (WPO). These models and supporting experimental data are reported in two Process Model Reports (PMRs), one for the WP and another for the WF (Waste Form). The Analyses and Models Reports (AMRs) comprising the WP PMR address the development of realistic models to account for the degradation of the outer barrier of both the DS and WP, based upon data generated by the Project. 


\section{QUALITY ASSURANCE}

\subsection{PROCEDURE FOR ANALYSES AND MODELS (AP-3.10Q)}

This work has been accomplished in accordance with Quality Assurance Requirements and Description (QARD) requirements as implemented by the Lawrence Livermore National Laboratory (LLNL) Yucca Mountain Project (YMP) Quality Procedures (QPs). This Analysis of Model Report (AMR) has been developed in accordance with Yucca Mountain Site Characterization Project Procedure entitled, "Analyses and Models" (AP-3.10Q, Revision 0, ICN $0)$.

\subsection{ACTIVITY PLANS (E-20-43/44, E-20-50, E-20-69, E-20-70 AND E-20-81)}

Threshold potentials were determined in accordance with Activity Plan AP-E-20-43/44. General corrosion rates in environments relevant to the repository were determined in accordance with Activity Plan AP-E-20-50. Activities E-20-43/44 and 50 are described in greater detail in the Scientific Investigation Plan (SIP) for Metal Barrier Selection and Testing (SIP-CM-01, Rev. 3). The procedures are compliant to the Office of Civilian Radioactive Waste Management (OCWRM) Quality Assurance (QA) Requirements. 


\section{CHECK COPY}

\section{COMPUTER SOFTWARE AND MODEL USAGE}

\subsection{SOFTWARE APPROVED FOR QA WORK}

No such software was required in support of the model presented here.

\subsection{SOFTWARE ROUTINES}

Calculations used to manipulate raw data were performed electronically in spreadsheets created with Microsoft Excel 97. The Microsoft Excel 97 that was used was bundled with Microsoft Office 97 Professional Edition for Windows 95/NT or Workstation 4.0 (SN \# 269-056-174). All spreadsheets have been assigned data tracking numbers, as shown in the Data Inventory provided as an attachment as per Section 9.0. Electronic copies of these spreadsheets and supporting data are provided on a 100 megabyte IBM-formatted ZIP disk provided as an attachment as per Section 9.0 . 


\section{INPUTS}

\subsection{PARAMETERS}

\subsubsection{Definition of Parameters}

\begin{tabular}{|c|c|}
\hline$a$ & dimension of weigh loss sample \\
\hline$b$ & dimension of weight loss sample \\
\hline$c$ & dimension of weight loss sample \\
\hline$b_{0}$ & coefficient in regression equation \\
\hline$b_{1}$ & coefficient in regression equation \\
\hline$b_{2}$ & coefficient in regression equation \\
\hline$f(y)$ & probability density function \\
\hline$i_{\text {corr }}$ & corrosion current density \\
\hline$i_{\text {pass }}$ & passive current density \\
\hline$k$ & parabolic rate constant in dry oxidation model \\
\hline$p$ & wall penetration due to corrosive attack \\
\hline$t$ & exposure time during weight loss measurement \\
\hline$t$ & time in dry oxidation model \\
\hline$u_{i}$ & mobility of the $i^{\text {th }}$ ion \\
\hline$w$ & measured weight loss \\
\hline$w_{\text {oxide }}$ & formula weight of oxide formed during dry oxidation \\
\hline$x$ & independent variable in regression equation \\
\hline$x$ & oxide thickness in dry oxidation model \\
\hline$x_{i}$ & measured parameter in sensitivity (error) analysis \\
\hline$y$ & dependent variable in regression equation \\
\hline$y$ & computed value in sensitivity (error) analysis \\
\hline$z_{i}$ & valence (charge) of the $i^{\text {th }}$ ion \\
\hline$C_{i}(\alpha)$ & molar concentration of the $\mathrm{i}^{\text {th }}$ ion in alpha phase \\
\hline$C_{i}(\beta)$ & molar concentration of the $i^{\text {th }}$ ion in the beta phase \\
\hline$D_{\text {oxide }}$ & diffusivity of reacting species through protective oxide \\
\hline$E_{\text {corr }}$ & corrosion potential \\
\hline$E_{\text {critical }}$ & critical potential - threshold for localized attack \\
\hline$E_{j}$ & junction potential - correction ior reference electrode junction \\
\hline & Faraday's constant \\
\hline$J_{\text {oxide }}$ & flux of reacting species through protective oxide \\
\hline$R$ & universal gas constant \\
\hline$R^{2}$ & regression coefficient \\
\hline$R I I$ & relative humidity \\
\hline $\begin{array}{l}R H_{\text {critical }} \\
T\end{array}$ & threshold relative humidity for humid air corrosion \\
\hline
\end{tabular}




\section{CHECK COPY}

$\begin{array}{ll}\sigma & \text { standard deviation } \\ \mu & \text { mean } \\ \rho & \text { density of Alloy } 22 \\ \rho_{\text {oxide }} & \text { density of oxide formed during dry oxidation } \\ \zeta_{\text {oxide }} & \text { stoichiometric coefficient for dry oxidation reaction }\end{array}$

\subsubsection{Determination of Input Parameters}

Input for this AMR includes bounding conditions for the local environment on the DS and WP surfaces, which include temperature, relative humidity, wetness (whether or not liquid phase water is present), electrolyte concentration in the liquid phase (chloride, buffer and $\mathrm{pH}$ ), and oxidant level. The detailed evolution of the environment on the DS surface is defined by a companion AMR entitled "Environment on the Surface of Drip Shield and Waste Package Outer Barrier" (Gdowski 1999). This work has been used to define the threshold relative humidity for humid air and aqueous phase corrosion, as well as a medium for testing Waste Package (WP) materials under what is now believed to be a worst-case scenario. This test medium is presented here as Simulated Saturated Water (SSW), and has a boiling point of approximately $120^{\circ} \mathrm{C}$.

As discussed in Section 6.4.1 of the AMR on environment (Gdowski 1999), hygroscopic salts may be deposited by aerosols and dust, and may be introduced with the backfill. They will be contained in seepage water that enters the drifts and the episodic water that flows through the drifts. Such hygroscopic salts enable aqueous solutions to exist at relative humidities below $100 \%$. The threshold relative humidity $\left(R H_{\text {critical }}\right)$ at which an aqueous solution can exist is defined as the deliquescence point. This threshold defines the condition necessary for aqueous electrochemical corrosion processes of a metal with salt deposits to occur at a given temperature. The deliquescence point of $\mathrm{NaCl}$ is relatively constant with temperature, and varies from 72 to $75 \%$. In contrast, the deliquescence point of $\mathrm{NaNO}_{3}$ has a strong dependence on temperature, ranging from an $\mathrm{RH}$ of $85 \%$ at $20^{\circ} \mathrm{C}$ to $70 \%$ at $90^{\circ} \mathrm{C}$. The implied equilibrium $\mathrm{RH}$ is $50.1 \%$ at $120.6^{\circ} \mathrm{C}$. The primary uncertainty in the threshold $\mathrm{RH}$ for humid air and aqueous phase corrosion is due to the presence of nitrate. For the time being, this threshold will be assumed to obey the following quadratic in temperature, which is a fit of the data deliquescence point data for $\mathrm{NaNO}_{3}$.

$$
R H_{\text {critical }}=-0.0045 \times T\left({ }^{\circ} \mathrm{C}\right)^{2}+0.2797 \times T\left({ }^{\circ} \mathrm{C}\right)+81.203
$$

As discussed in Section 6.5.2 of the AMR on environment (Gdowski 1999), the evaporative concentration of $\mathrm{J}-13$ water results in the concentration of $\mathrm{Na}^{+}, \mathrm{K}^{+}, \mathrm{Cl}^{-}$, and $\mathrm{NO}_{3}^{-}$. The concentration of $\mathrm{HCO}_{3}{ }^{-}$reaches a constant level, while the concentrations of $\mathrm{F}^{-}$and $\mathrm{SO}_{4}{ }^{2-}$ initially increase, but eventually fall due to precipitation. Ultimately, the $F^{-}$drops below the level of detection. The Simulated Saturated Water (SSW) used for testing is an abstract embodiment of this observation. The SSW formulation is based upon the assumption that evaporation of J-13 eventually leads to a sodium-potassium-chloride-nitrate solution. The absence of sulfate and carbonate in this test medium is believed to be conservative, in that carbonate would help buffer $\mathrm{pH}$ in any occluded geometry such as a crevice. 


\section{CHECK COPY}

Experimental data from the scientific and technical literature, the Long Term Corrosion Test Facility (LTCTF) and Cyclic Polarization (CP) measurements and crevice corrosion experiments at both LLNL are used as a basis for this process level model.

\subsection{CRITERIA}

The DS is intended to extend the life of the WP so that necessary performance requirements can be met. The applicable requirements reproduced below are from Section 1.2, "System Design Criteria" of Uncanistered Spent Nuclear Fuel Disposal Container System Description Document (CRWMS 1999).

"The disposal container shall be designed such that no more than 1 percent of all waste packages breach during the first 1,000 years after emplacement (breaching is defined as an opening through the wall of the waste package through which advective or diffusive transport of gas or radionuclides can occur)." (Section 1.2.1.1)

"The disposal container shall be designed such that for 10,000 years after permanent closure of the repository the release rate of any radionuclide from all waste packages shall not exceed one part in 100,000 per year of the inventory of that radionuclide calculated to be present at 1,000 years following permanent closure; provided, that this requirement does not apply to any radionuclide which is released at a rate less than 0.1 percent of the calculated total release rate limit. The calculated total release rate limit shall be taken to be one part in 100,000 per year of the inventory of radioactive waste, originally emplaced in the underground facility, that remains after 1,000 years of radioactive decay." (Section 1.2.1.4)

The analyses contained in this AMR serve as a basis to determine whether or not the performance requirements for the DS can be met. The performance requirements of the DS are dependent upon the requirements for systems in the repository.

\subsection{CODES AND STANDARDS}

\subsubsection{Standard Test Media}

G. E. Gdowski, Formulation and Make-up of Simulated Dilute Water (SDW), Low Ionic Content Aqueous Solution, Yucca Mountain Project, Lawrence Livermore National Laboratory, Livermore, CA, TIP-CM-06, Revision CN TIP-CM-06-0-2, April 4, 1997, Table 1, p. 3.

G. E. Gdowski, Formulation and Make-up of Simulated Concentrated Water (SCW), High Ionic Content Aqueous Solution, Yucca Mountain Project, Lawrence Livermore National Laboratory, Livermore, CA, TIP-CM-07, Revision CN TIP-CM-07-0-2, April 4, 1997, Table 1, pp. 3-4.

G. E. Gdowski, Formulation and Make-up of Simulated Acidic Concentrated Water (SAW), High Ionic Content Aqueous Solution, Yucca Mountain Project, Lawrence Livermore National Laboratory, Livermore, CA, TIP-CM-08, Revision CN TIP-CM-08-0-2, April 4, 1997, Table 1, p. 3. 


\subsubsection{Cyclic Polarixation Measurements}

Standard Reference Test Method for Making Potentiostatic and Potentiodynamic Anodic Polarization Measurements, Designation G 5-87, 1989 Annual Book of ASTM Standards, Section 3, Vol. 3.02, pp. 79-85.

\subsubsection{General Corrosion Measurments}

Standard Practice for Preparing, Cleaning, and Evaluating Corrosion Test Specimens, Designation G 1-81, 1987 Annual Book of ASTM Standards, Section 3, Vol. 3.02, pp. 89-94, Subsection 8 - Calculation of Corrosion Rate, $A$ ppendix X1 - Densities for a Variety of Metals and Alloys. 


\section{CHECK COPY}

\section{ASSUMPTIONS}

\subsection{DRY OXIDATION}

Dry oxidation is assumed to occur at any relative humidity $(\mathrm{RH})$ below the threshold for humid air corrosion (HAC):

$R H<R H_{\text {critical }}$

This threshold RH for HAC $\left(R H_{\text {critical }}\right)$ is assumed obey Equation 4-1, which is based upon the AMR entitled "Environment on the Surface of Drip Shield and Waste Package Outer Barrier" (Gdowski 1999). This process is assumed to result in the formation of an adherent, protective oxide film of uniform thickness. The rate of dry oxidation will be assumed to be limited by mass transport through the growing metal oxide film. Consequently, the oxide thickness will obey the following parabolic growth law (film thickness proportional to the square root of time). Reasonable values of the parabolic rate constant will be assumed, as discussed in Section 6.1.

\subsection{HUMID AIR CORROSION}

$\mathrm{HAC}$ is assumed to occur at any $\mathrm{RH}$ above the threshold, provided that there is no dripping:

$$
R H \geq R H_{\text {critical }}
$$

This threshold RH for HAC $\left(R H_{\text {critical }}\right)$ is assumed to obey Equation 4-1, which is based upon the AMR entitled "Environment on the Surface of Drip Shield and Waste Package Outer Barrier" (Gdowski 1999). As a bounding worst-case assumption, it will be assumed that the rate of HAC is identical to the largest observed rate for aqueous phase corrosion during the period where $\mathrm{HAC}$ is operable. It will also be assumed that the corrosion rate is constant, and does not decay with time. Less conservative corrosion models assume that the rate decays with time.

\subsection{AQUEOUS PHASE CORROSION}

At a given surface temperature, the existence of liquid-phase water on the DS depends upon the presence of a salt and mineral deposit. In the presence of such a deposit, a liquid-phase can be established at a higher temperature than otherwise possible. In the model discussed here, it is assumed that two conditions must be met for aqueous phase corrosion: dripping water; and RH above the deliquescence point of the deposit at the temperature of the DS surface.

$$
R H \geq R H_{\text {critical }}
$$

This threshold RH for HAC ( $R H_{\text {critical }}$ ) is assumed obey Equation 4-1, which is based upon the AMR entitled "Environment on the Surface of Drip Shield and Waste Package Outer Barrier" (Gdowski 1999). For the time being, the composition of the electrolyte formed on the DS surface is assumed to be that of SCW below $100^{\circ} \mathrm{C}$, and that of Simulated Saturated Water (SSW) above $100^{\circ} \mathrm{C}$. It will be assumed that the corrosion rate is constant, and does not decay 
with time. Less conservative corrosion models assume that the rate decays with time.

\subsection{DRIPPING CONDENSATE FROM INNER SURFACE OF DRIP SHIELD}

Once the temperature of the DS drops below the dew point, condensation can occur on the inner surface. While clinging to the underside of the WP, it will be assumed that this electrolyte is essentially pure water. As a worst case scenario, measurements made with SDW will be used as the basis of model predictions. Ultimately, this condensate can then form droplets that fall and impinge the underlying WP surface, provided that the droplets are sufficiently large so that they can fall through the temperature gradient towards the WP without complete evaporation.

\subsection{FLOW THROUGH OPENINGS BETWEEN DRIP SHIELDS}

It is believed that the final analysis will show that general corrosion does not limit the life of the DS and that no significant LC occurs. However, ground movement may cause displacement of adjacent drip shiclds along the drift axis, thereby opening pathways that enable dripping water to reach the WP. Such displacement may also lead to sufficient stress to cause either SCC or HIC, and a more catastrophic failure of the DS. For a given mass flow of water contacting the outer surface of the DS, the fraction passing through an opening to the WP is assumed to be proportional to the following multiplication factor $\left(\Theta_{\text {shield }}\right)$ :

$\Theta_{\text {shield }}=\frac{A_{\text {opening }}}{A_{\text {shield }}}$

where $A_{\text {opening }}$ is the projected area of the opening on the floor of the drift, and $A_{\text {shield }}$ is the projected area of the DS on the floor of the drift. If the DS fails due to SCC, a multiplication factor of one will be assumed.

\subsection{THRESHOLD FOR LOCALIZED CORROSION}

If the open circuit corrosion potential ( $E_{\text {corr }}$ ) is less than the threshold potential for localized corrosion ( $\left.E_{\text {critical }}\right)$, it will be assumed that no localized corrosion occurs.

$E_{\text {corr }}<E_{\text {crisical }}$

Threshold values have been determined for various representative environments, as discussed in Section 6.4 .

\subsection{EFFECT OF GAMMA RADIOLYSIS ON CORROSION POTENTIAL}

It will be assumed that the effects of oxidant can be accounted for through the open circuit corrosion potential $\left(E_{\text {corr }}\right)$. Based upon published data described in Section 6.5.2, it is believed that the shift in corrosion potential due to gamma radiolysis will be much less than $200 \mathrm{mV}$. 


\subsection{MICROBIAL GROWTH}

In the present model, it is assumed that the effect of microbial growth on corrosion potential is not significant. In general, titanium is very resistant to microbial influenced corrosion (MIC).

\subsection{PHASE INSTABILITY}

Pure titanium is an allotropic element, meaning that it has more than one crystallographic form (Gdowski 1997). Above $883^{\circ} \mathrm{C}$ it has the body-centered cubic (bcc) crystal structure, which is called the beta $(\beta)$ phase. Below $883^{\circ} \mathrm{C}$, it transforms to a hexagonal closed-packed (hcp) structure, which is called the alpha ( $\alpha$ ) phase. Both Ti Grs 7 and 16 are $\alpha$-phase alloys and have very small additions of $\mathrm{Pd}$. The solubility of $\mathrm{Pd}$ in these materials is about 1 weight percent at $400^{\circ} \mathrm{C}$. The nominal concentrations of Pd in both Ti Grs 7 and 16 are well below the solubility limit at this temperature (Gdowski 1997). Titanium-palladium intermetallic compounds capable of being formed in this system have not been reported to occur in $\mathrm{Ti} \mathrm{Gr} 7$ and 16 with normal heat treatments.

The temperature of the DS is limited by the temperature of the underlying WP. The transition from $\alpha$ - to $\beta$-phase titanium should not occur at these temperatures. As discussed in the companion AMR on general and localized corrosion of the Waste Package Outer Barrier (WPOB), it is assumed that the WP temperature is kept below $300^{\circ} \mathrm{C}$. With this constraint, it is further assumed that the impact of aging and phase instability on the corrosion of Ti Gr 7 will be insignificant. 


\section{ANALYSIS}

\subsection{DRY OXIDATION}

Dry oxidation is assumed to occur at any relative humidity $(\mathrm{RH})$ below the threshold for HAC.

$$
R H<R H_{\text {criical }}
$$

This process is assumed to result in the formation of an adherent, protective oxide film of uniform thickness. It will be assumed that the protective oxide film is primarily $\mathrm{TiO}_{2}$. The oxidation reaction given as (Welsch et al. 1996):

$\mathrm{Ti}+\mathrm{O}_{2} \longrightarrow \mathrm{TiO}_{2}$

The rate of dry oxidation will be assumed to be limited by mass transport through this growing metal oxide film. Fick's first law is applied, assuming a linear concentration gradient across the oxide film of thickness $x$ :

$$
J_{\text {oxide }}=-D_{\text {oxide }} \frac{\partial C}{\partial x} \approx-D_{\text {oxde }} \frac{\Delta C}{x}
$$

where $J_{\text {oxide }}$ is the molar flux of the reacting species in the oxide, $D_{\text {oxide }}$ is the diffusivity of the reacting species in the oxide, $\Delta C$ is the corresponding differential molar concentration. Oxide growth is related to the flux by:

$$
\frac{d x}{d t}=\frac{\zeta_{\text {oxide }} \times w_{\text {oxide }} \times J_{\text {oxide }}}{\rho_{\text {oxide }}}
$$

where $\zeta_{\text {oxide }}$ is the stoichiometric coefficient (moles of oxide per mole of diffusing species), $w_{\text {oxide }}$ is the formula weight of the oxide, and $\rho_{\text {oxide }}$ is the density of the oxide. Integration shows that the oxide thickness should obey the following parabolic growth law (Wagner's Law), where the film thickness is proportional to the square root of time:

$x=\sqrt{x_{0}^{2}+k \times t}$

where $x_{0}$ is the initial oxide thickness, $x$ is the oxide thickness at time $t$, and $k$ is a temperaturedependent parabolic rate constant. More specifically, $k$ is defined as follows:

$k=\frac{2 \times \zeta_{\text {oxide }} \times w_{\text {oxide }} \times D_{\text {oxide }} \times \Delta C}{\rho_{\text {oxide }}}$

To facilitate an approximate calculation, published values of $k_{p w}$ can be used (Wclsch et al. 1996). From Figure 25 of this reference, it is concluded that all observed values of $k_{p w}$ fall below a line defined by: 


\section{CHECK COPY}

$\log \left[k_{p w}\left(m g^{2} \mathrm{~cm}^{-4} \mathrm{~min}^{-1}\right)\right]=-4.004384 \times\left(\frac{1}{T(K)}\right)+4.383507 \times 10^{-3}$

where $T$ is defined as the absolute temperature. This can be converted to the parabolic rate constant, $k\left(\mathrm{~m}^{2} \mathrm{~s}^{-1}\right)$, by dividing by the square of the density and multiplying by an appropriate correction factor. The density of $\mathrm{TiO}_{2}$ is approximately $4.26 \mathrm{~g} \mathrm{~cm}^{-3}$ (CRC 1978-79 p. B178). The highest temperature is expected to be approximately $350^{\circ} \mathrm{C}(623 \mathrm{~K})$, which corresponds to the limit for the fuel cladding. The value of $k_{p w}$ corresponding to this upper limit is $0.9953 \mathrm{mg}^{2}$ $\mathrm{cm}^{-4} \mathrm{~min}^{-1}$. The corresponding value of $k$ is $9.14 \times 10^{-14} \mathrm{~m}^{2} \mathrm{~s}^{-1}\left(2.88 \times 10^{6}\right.$ square microns per year). Thus, a layer of $\mathrm{TiO}_{2}$ could grow to a thickness of 1698 microns after one year at $350^{\circ} \mathrm{C}$ (about 1698 microns per year). Given how high this rate is, it is recommended that dry oxidation of the Ti Gr 7 be accounted for through application of the parabolic law. The above expression represents a conservative upper bound, based upon the published literature. Actually values of the rate constant may be less by an order of magnitude.

\subsection{HUMID AIR CORROSION}

HAC is assumed to occur above a threshold $\mathrm{RH}$, provided that there is no dripping:

$R H \geq R H_{\text {critical }}$

This threshold RH for HAC $\left(R H_{\text {critical }}\right)$ is assumed obey Equation 4-1, which is based upon the AMR entitled "Environment on the Surface of Drip Shield and Waste Package Outer Barrier" (Gdowski 1999). The existence of this threshold is due to the dependence of water adsorption on RH.

Despite significant experimental work, there continues to be significant uncertainty in the threshold RH for humid air and aqueous phase corrosion. Furthermore, other sources of data indicate that it may be reasonable to consider $\mathrm{HAC}$ at a relative humidity below that predicted with Equation $4-1$ at $20^{\circ} \mathrm{C}$. The approximate number of water monolayers on typical metal surfaces as a function of RH is given by Leygraf (1995) and repeated in Table 6-1 of the companion AMR on the general and localized corrosion of the WPOB (Farmer et al. 1999). Based upon this data, it is reasonable to consider the possibility of $\mathrm{HAC}$ at only $40 \% \mathrm{RH}$. This is the point at which it may be possible for two monolayers of water can exist on the WP surface. It is therefore recommended that a sensitivity analysis be performed. During this analysis, it should be assumed that the threshold is uniformly distributed between 40 to $100 \% \mathrm{RH}$, limits corresponding to the $0^{\text {th }}$ and $100^{\text {th }}$ percentiles, respectively.

It will be assumed that HAC can be treated as uniform general corrosion. As a bounding worstcase assumption, it will be assumed that the rate of HAC is identical to the largest observed rate for aqueous phase corrosion during the period where $\mathrm{HAC}$ is operable. It will also be assumed that the corrosion rate is constant, and does not decay with time. 


\section{CHECK COPY}

\subsection{AQUEOUS PHASE CORROSION}

At a given surface temperature, the existence of liquid-phase water on the WP depends upon the presence of a salt and mineral deposit. In the presence of such a deposit, a liquid-phase can be established at a higher temperature than otherwise possible. In the model discussed here, it is assumed that two conditions must be met for aqueous phase corrosion: dripping water; and $\mathrm{RH}$ above the deliquescence point of the deposit at the temperature of the WP surface.

$$
R H \geq R H_{\text {critical }}
$$

This threshold RH for HAC $\left(R H_{\text {critical }}\right)$ is assumed obey Equation 4-1, which is based upon the AMR entitled "Environment on the Surface of Drip Shield and Waste Package Outer Barrier" (Gdowski 1999). For the time being, the composition of the electrolyte formed on the WP surface is assumed to be that of SCW below $100^{\circ} \mathrm{C}$, and that of SSW above $100^{\circ} \mathrm{C}$. It will be assumed that the corrosion rate is constant, and does not decay with time. Less conservative corrosion models assume that the rate decays with time.

\subsection{LOCALIZED CORROSION}

\subsubsection{Threshold Potential for Ti Gr 7}

The localized corrosion model for the titanium DS assumes that localized attack occurs if the open circuit corrosion potential $\left(E_{\text {corr }}\right)$ exceeds the threshold potential for breakdown of the passive film ( $\left.E_{\text {critical }}\right)$ :

$$
E_{\text {corr }} \geq E_{\text {criical }}
$$

\subsubsection{Cyclic Polarization in Synthetic Concentrated J-13 Waters}

The Project has used cyclic polarization (CP) to determine threshold potentials for titanium alloys in various test media relevant to the environment expected in the repository. Relevant test environments are assumcd to include Simulated Dilute Water (SDW), Simulated Concentratcd Water (SCW) and Simulated Acidic Concentrated Water (SAW) at 30,60 and $90^{\circ} \mathrm{C}$, as well as Simulated Saturated Water (SSW) at 100 and $120^{\circ} \mathrm{C}$. The compositions of the first three environments are given in Tables 6-3 and 6-4 of the AMR on general and localized corrosion oi the WPOB (Farmer et al. 1999). The compositions of these test media are based upon the work of Gdowski as documented in TIP-CM-06 Rev. 0 (Gdowski 1997a), TIP-CM-07 Rev. 0 (Gdowski 1997b) and TIP-CM-08 Rev. 0 (Gdowski 1997c). The SSW composition has been recently developed and is documented in a companion AMR on the subject of WP surface environment (Gdowski 1999).

Cyclic polarization measurements have been based on ASTM G 5-87 [ASTM 1989a]. Any necessary deviations are noted in the corresponding Scientific Notebooks. Representative cyclic polarization curves are shown in Figures 6-1 through 6-5 of this report. In general, these curves exhibit complete passivity (no passive film breakdown) between the Corrosion Potential and the point defined as Threshold Potential 1. Threshold Potential 1 is in the range where the onset of 


\section{CHECK COPY}

oxygen evolution is expected and is defined by a large excursion in anodic current.

\subsubsection{Correlation of Potential vs. Temperature Data for Various Test Media}

Values of corrosion and threshold potentials have been correlated as a function of temperature for the conditions of interest. These correlated data are shown in Figures 6-6 through 6-9. In general, it has been found that these potential verses temperature data can be represented by the following simple regression equation:

$y=b_{0}+b_{1} x+b_{2} x^{2}$

where $y$ is either the corrosion or threshold potential ( $\mathrm{mV}$ vs. $\mathrm{Ag} / \mathrm{AgCl}$ ), and $x$ is the temperature $\left({ }^{\circ} \mathrm{C}\right)$. The correlations for $E_{\text {corr }}$ and $E_{\text {critical }}$ are summarized in Table 6-1.

It is assumed that the specifications for the DS material include allowable values for $E_{\text {corr }}$ and $E_{\text {critical. }}$. Acceptance of the material requires that: (1) the messured value of $E_{c o r r}$ in a particular environment cannot exceed the value calculated with the corresponding correlation in Table 6-1 by more than $325 \mathrm{mV}$; and (2) the measured value of $E_{\text {critical }}$ in a particular environment cannot be less than the value calculated with the corresponding correlation in Table $6-1$ by more than $325 \mathrm{mV}$.

The correlations given in Table 6-1 were used to calculate the values of $E_{\text {corr }}$ and $E_{\text {critical }}$ shown in Table 6-2 for SDW, SCW, SAW and SSW. Table 6-2 shows the difference between $E_{c r i t}$ and $E_{\text {corr }}$ (column heading Diff.) is never less than $651 \mathrm{mV}$ between 20 and $150^{\circ} \mathrm{C}$. Therefore, implementation of the potential-based specification will prevent the use of heats of material that would be prone to passive film instability or localized corrosion. The cost of such performance would be associated with the quantity of rejected material (assumed to be approximately 20\%). The specification can be changed to allow more material to be accepted, but with greater risk of localized corrosion.

In an ideal case, the crevice corrosion temperature can be estimated from the intersection of the lines representing the corrosion and threshold potentials at elevated temperature. To force crevice corrosion to occur in the model, $E_{\text {corr }}$ and $E_{\text {critical }}$ can simply be equated over temperature ranges of uncertainty $\left(90\right.$ to $\left.120^{\circ} \mathrm{C}\right)$. Additional data is needed to fill this void. 


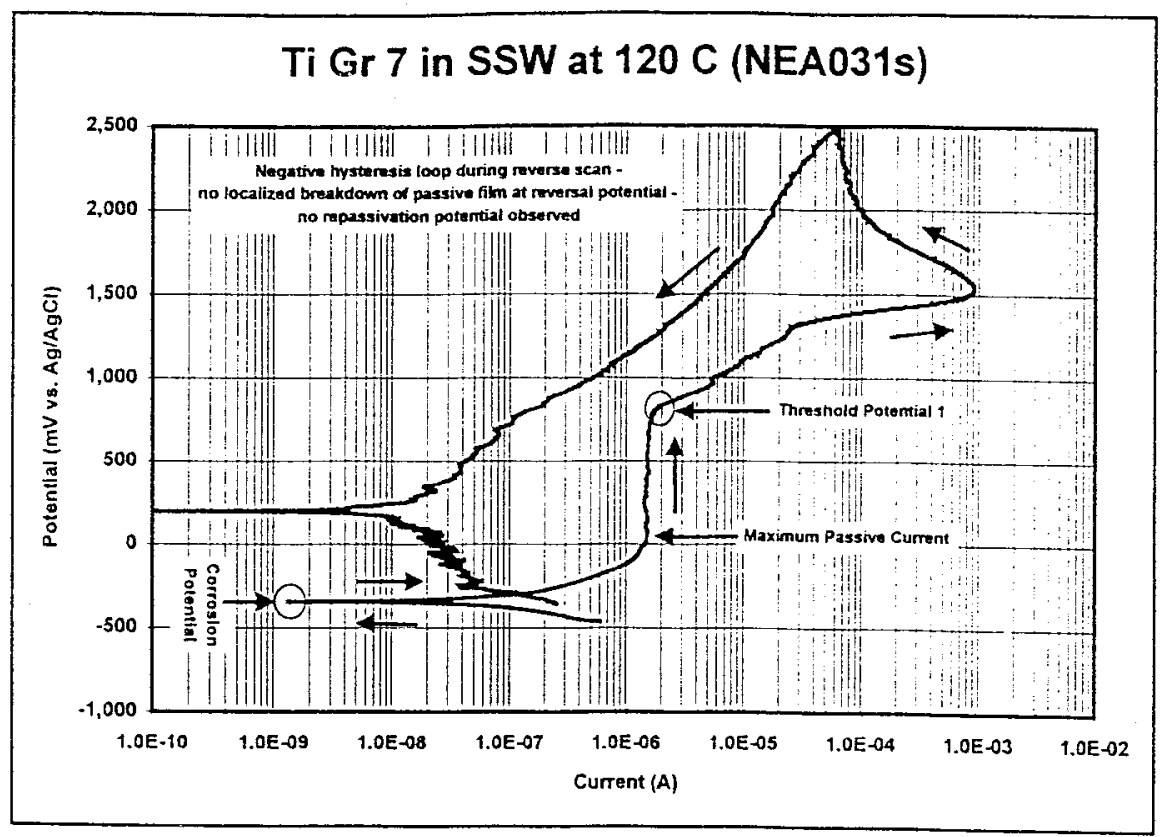

Figure 6 - 1. Titanium Grade 7 in SSW at 120 Centigrade (NEA031S) [DTN \# ].

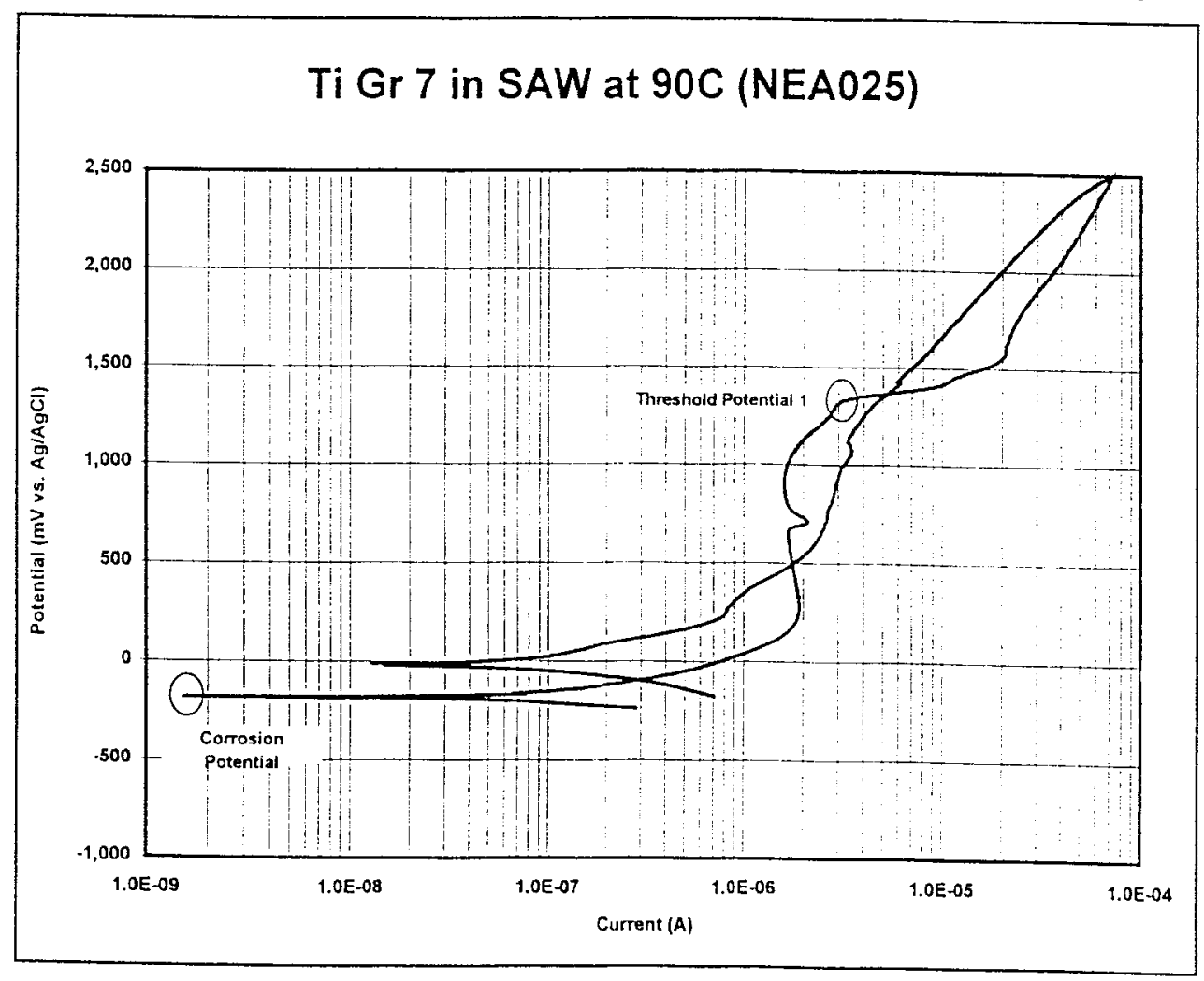

Figure 6 - 2. Titanium Grade 7 in SAW at 90 Centigrade (NEAO25) [DTN \# ]. 


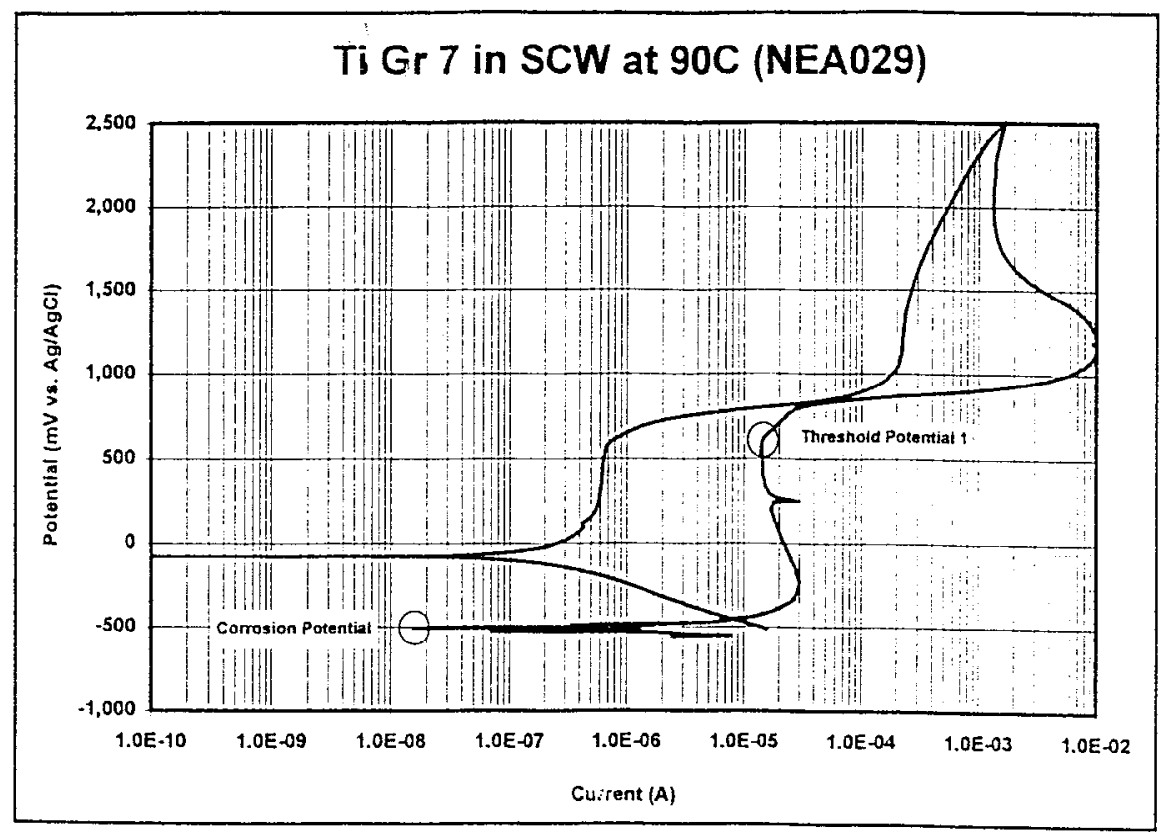

Figure 6 - 3. Titanium Grade 7 in SCW at 90 Centigrade (NEA029) [DTN \#].

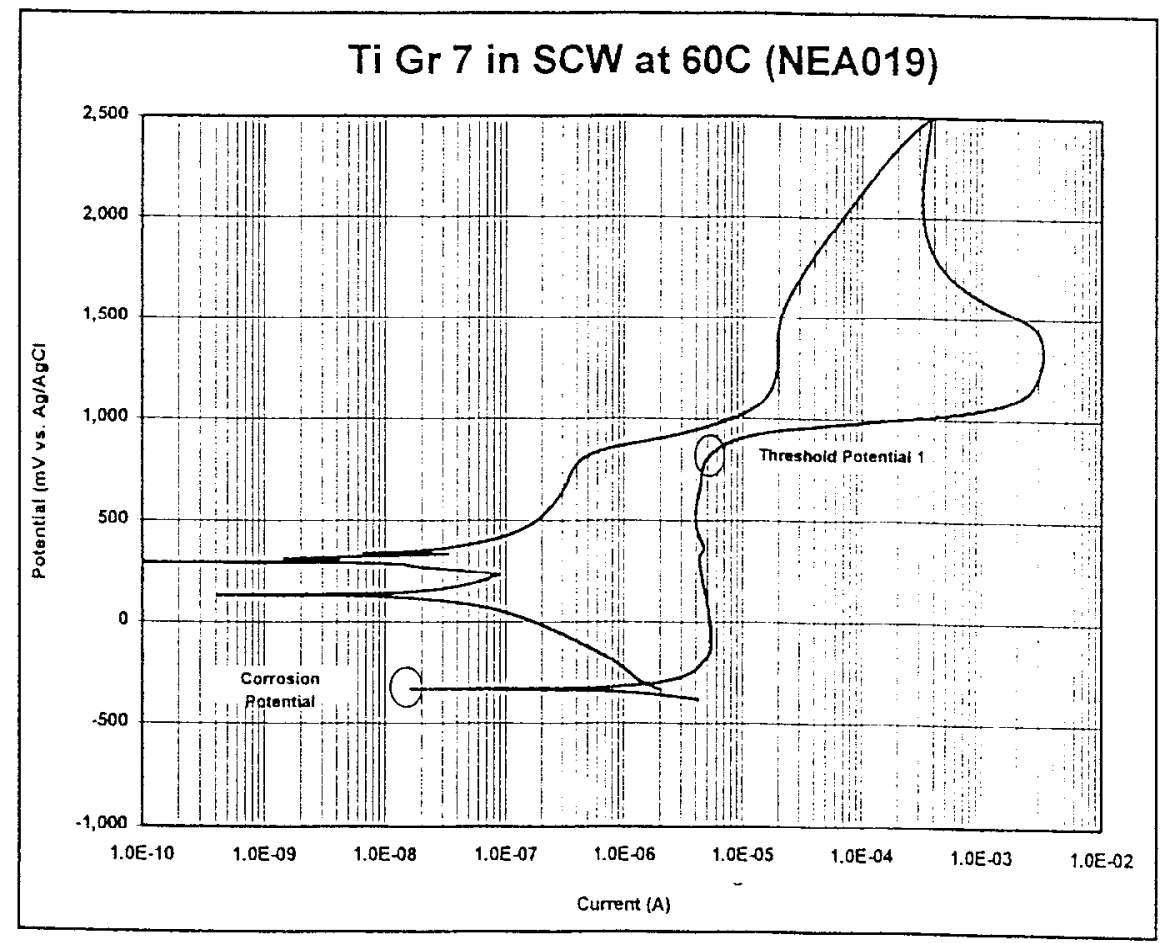

Figure 6 - 4. Titanium Grade 7 in SCW at 60 Centigrade (NEA019) [DTN \#]. 


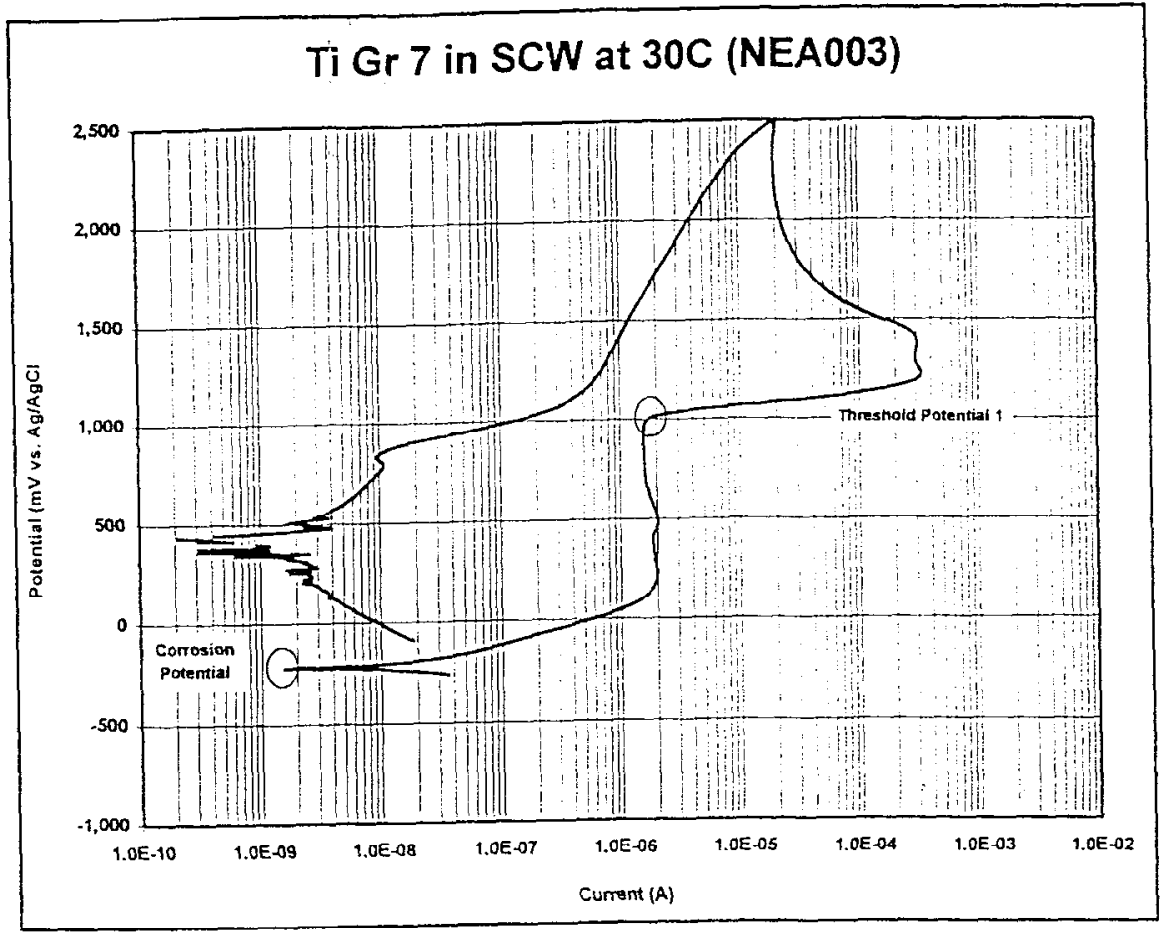

Figure 6 - 5. Titanium Grade 7 in SCW at 90 Centigrade (NEA003) [DTN \# ].

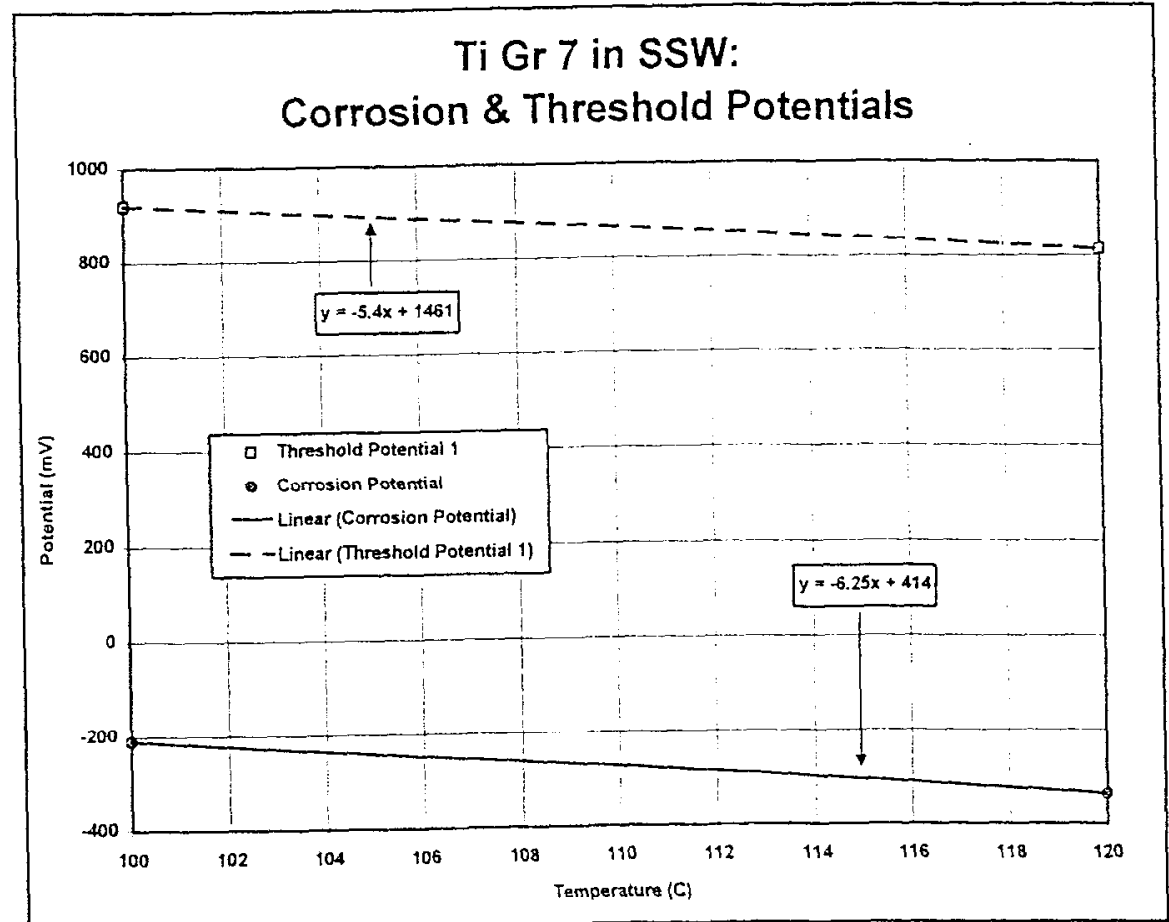

Figure 6-6. Corrosion \& Threshold Potentials of Titanium Grade 7 in SSW (NEA031s) [DTN \#]. 


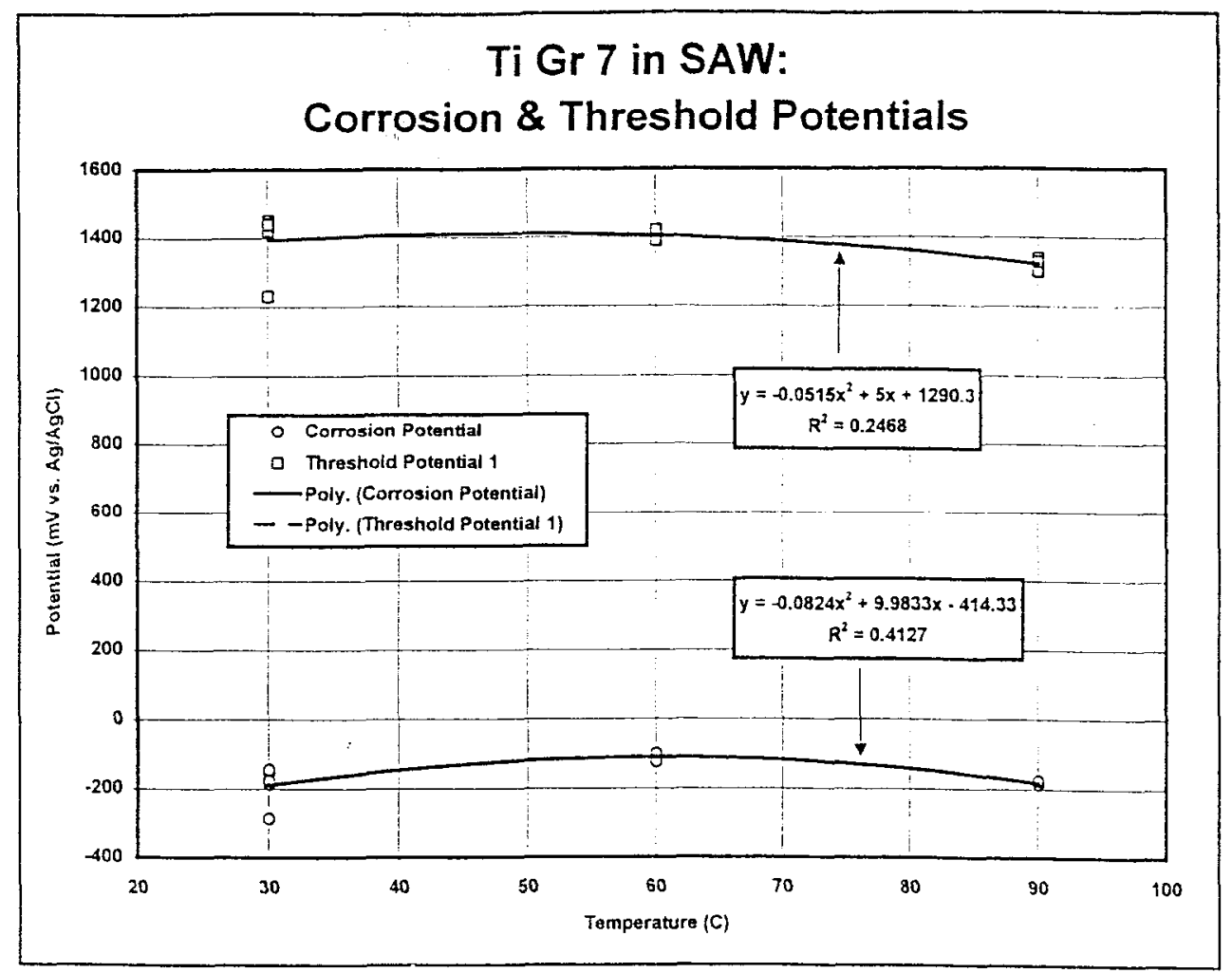

Figure 6 - 7. Corrosion \& Threshold Potentials for Titanium Grade 7 in SAW [DTN \#]

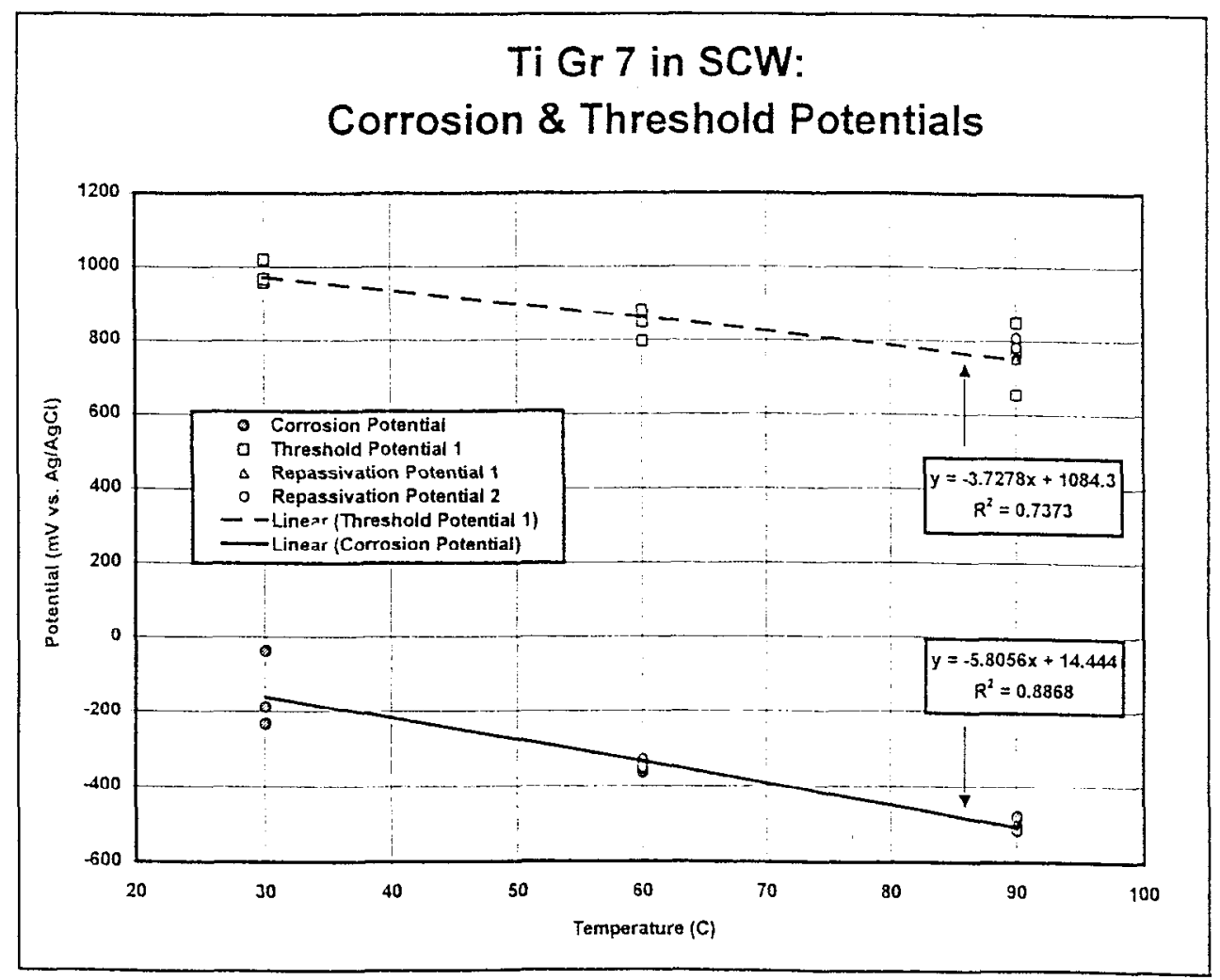

Figure 6 - 8. Corrosion \& Threshold Potentials for Titanium Grade 7 in SCW [DTN \# ]. 


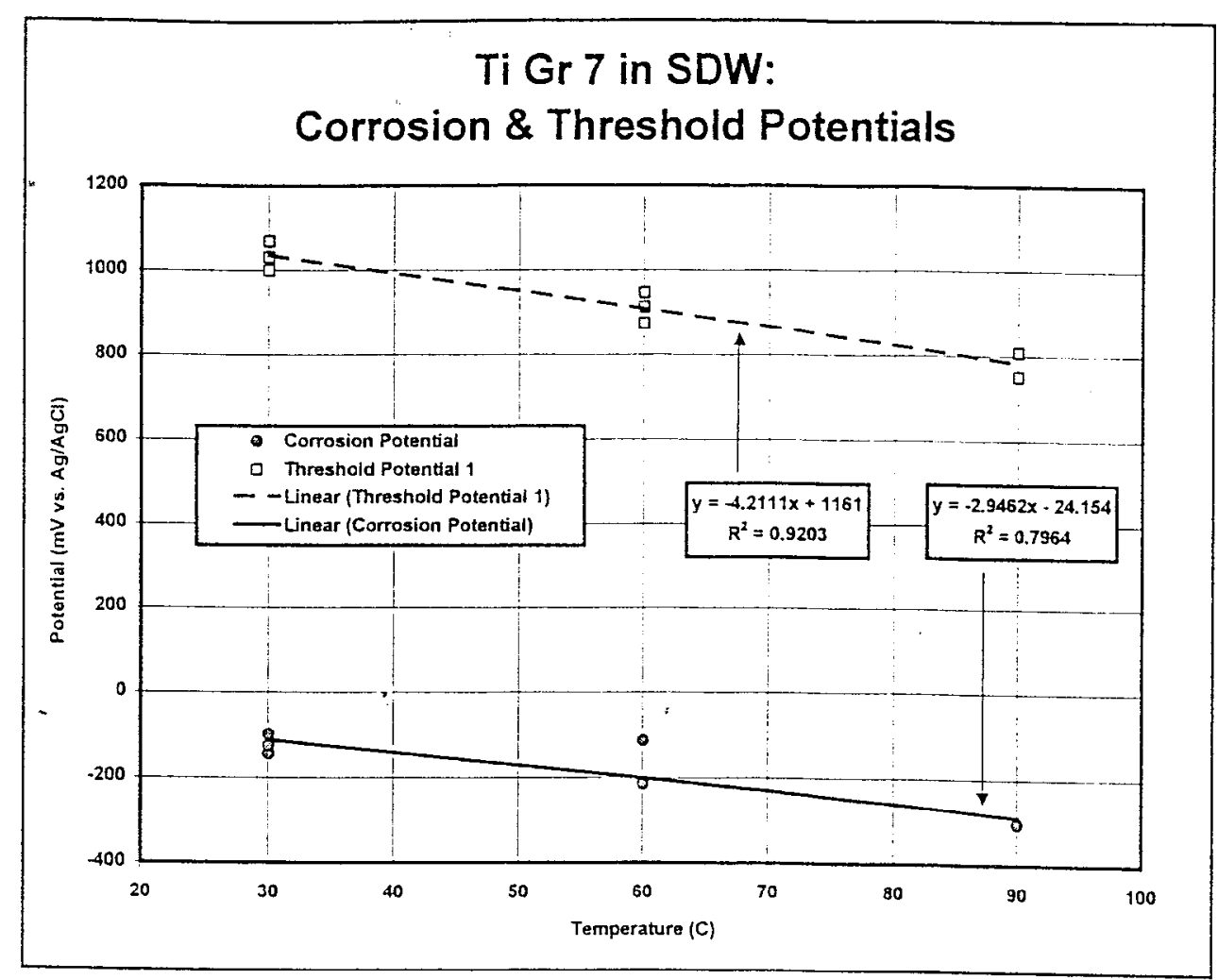

Figure 6 - 9. Corrosion \& Threshold Potentials for Titanium Grade 7 in SDW [DTN \# ].

Table 6 - 1. Summary of Correlated Corrosion and Threshold Potential Data [DTN \# ]

\begin{tabular}{|l|l|l|c|c|c|c|}
\hline Medium & Potential & Parameter & $\mathrm{b}_{0}$ & $\mathrm{~b}_{1}$ & $\mathrm{~b}_{2}$ & $\mathrm{R}^{2}$ \\
\hline SDW & Corrosion & $\mathrm{E}_{\text {corr }}$ & -24.154 & -2.9462 & & 0.7964 \\
\hline SDW & Threshold 1 & $\mathrm{E}_{\text {critical }}$ & 1161 & -4.2111 & & 0.9203 \\
\hline & & & & & & \\
\hline SCW & Corrosion & $E_{\text {corr }}$ & 14.444 & -5.8056 & & 0.8868 \\
\hline SCW & Threshold 1 & $E_{\text {critical }}$ & 1084.3 & -3.7278 & & 0.7373 \\
\hline & & & & & & \\
\hline SAW & Corrosion & $E_{\text {corr }}$ & -414.3 & 9.9833 & -414.33 & 0.4127 \\
\hline SAW & Threshold & $E_{\text {critical }}$ & 1290.3 & 5 & -0.0515 & 0.2468 \\
\hline & & & & & & \\
\hline SSW & Corrosion & $F_{\text {corr }}$ & 414 & -6.25 & & None \\
\hline SSW & Threshold 1 & $E_{\text {critical }}$ & 1461 & -5.4 & & None \\
\hline
\end{tabular}




\section{CHECK COPY}

Table 6 - 2. Values of $E_{\text {corr }}$ and $E_{\text {critical }}$ Based on Correlated Cyclic Polarization Data [DTN \#]

\begin{tabular}{|c|c|c|c|c|c|c|c|c|c|c|c|c|}
\hline & SDW & SDW & SDW & SCW & SCW & SCW & SAW & SAW & SAW & SSW & SSW & SSW \\
\hline $\mathrm{T}$ & $E_{\text {corr }}$ & $E_{\text {critical }}$ & Diff. & $E_{\text {corr }}$ & $E_{\text {critical }}$ & Diff. & $E_{\text {corr }}$ & $E_{\text {crittcal }}$ & Diff. & $E_{\text {corr }}$ & $E_{\text {critical }}$ & Diff. \\
\hline${ }^{\circ} \mathrm{C}$ & $\mathrm{mV}$ & $\mathrm{mV}$ & $\mathrm{mV}$ & $\mathrm{mV}$ & $m \mathrm{~V}$ & $\mathrm{mV}$ & $\mathrm{mV}$ & $\mathrm{mV}$ & $\mathrm{mV}$ & $\mathrm{mV}$ & MV & MV \\
\hline 20 & -83 & 1077 & 1160 & -102 & 1010 & 1111 & -248 & 1370 & 1617 & 289 & 1353 & 1064 \\
\hline 30 & -113 & 1035 & $\mid 1147$ & -160 & 972 & 1132 & -189 & 1394 & 1583 & 227 & 1299 & 1073 \\
\hline 40 & -142 & 993 & 1135 & -218 & 935 & 1153 & -147 & 1408 & 1555 & 164 & 1245 & 1081 \\
\hline 50 & -171 & 950 & 1122 & -276 & 898 & 1174 & -121 & 1412 & 1533 & 102 & 1191 & 1090 \\
\hline 60 & -201 & 908 & 1109 & -334 & 861 & 1195 & -112 & 1405 & 1517 & 39 & 1137 & 1098 \\
\hline 70 & -230 & 866 & 1097 & -392 & 823 & 1215 & -119 & 1388 & 1507 & -24 & 1083 & 1107 \\
\hline 80 & -260 & 824 & 1084 & -450 & 786 & 1236 & -143 & 1361 & 1504 & -86 & 1029 & 1115 \\
\hline 90 & -289 & 782 & 1071 & -508 & 749 & 1257 & -183 & 1323 & 1506 & -149 & 975 & 7124 \\
\hline 100 & -319 & 740 & 1059 & -566 & 712 & 1278 & -240 & 1275 & 1515 & -211 & 921 & 1132 \\
\hline 110 & -348 & 698 & 1046 & -624 & 674 & 1298 & -313 & 1217 & 1530 & -274 & 867 & 1141 \\
\hline 120 & -378 & 656 & 1033 & -682 & 637 & 1319 & -403 & 1149 & 1552 & -336 & 813 & 1149 \\
\hline 130 & -407 & 614 & 1021 & -740 & 600 & 1340 & -509 & 1070 & 1579 & -399 & 759 & 1158 \\
\hline 140 & -437 & 571 & 1008 & -798 & 562 & 1361 & -632 & 981 & 1613 & -461 & 705 & 1166 \\
\hline 150 & -466 & 529 & 995 & -856 & 525 & 1382 & -771 & 882 & 1652 & -524 & 651 & 1175 \\
\hline
\end{tabular}

\subsubsection{Correction of Measured Potential for Junction Potential}

It is important to understand the error in the potential measurements due to the junction potential. $\Lambda$ correction has been performed based upon the Henderson Equation (Bard and Faulkner 1980). Calculated values of the isothermal junction potentials are summarized in Table 6-7 of the AMR on general and localized corrosion of the WPOB (Farmer et al. 1999), which is repeated below at Table 6-3. The thermal gradient across the Luggin probe with saturated $\mathrm{KCl}$ should produce no significant potential.

Table 6 - 3. Summary of Junction Potential Corrections for Cyclic Polarization (Volts) [DTN \#].

\begin{tabular}{|c|c|c|c|c|}
\hline$T\left({ }^{\circ} \mathrm{C}\right)$ & SDW & SCW & SAW & SSW \\
\hline 30 & $2.650 \mathrm{E}-03$ & $2.729 \mathrm{E}-02$ & $-3.550 \mathrm{E}-03$ & $-2.291 \mathrm{E}-03$ \\
\hline 60 & $2.912 \mathrm{E}-03$ & $2.999 \mathrm{E}-02$ & $-3.902 \mathrm{E}-03$ & $-2.518 \mathrm{E}-03$ \\
\hline 90 & $3.175 \mathrm{E}-03$ & $3.269 \mathrm{E}-02$ & $-4.253 \mathrm{E}-03$ & $-2.745 \mathrm{E}-03$ \\
\hline
\end{tabular}

\subsection{RATES OF GENERAL AQUEOUS-PHASE CORROSION}

Localized corrosion (LC) rates will be assumed if the open circuit corrosion potential $\left(E_{c o r r}\right)$ exceeds the threshold potential $\left(E_{\text {critical }}\right)$. General corrosion $(\mathrm{GC})$ rates will be assumed if the threshold potential is not exceeded. GC rates will be estimated with weight-loss data from the Long Term Corrosion Test Facility (LTCTF) (Estill 1998). LC rates and failure mode characteristics (e.g., number failure sites and opening size) will be estimated from experimental measurements of crevice corrosion made at LLNL. Since pitting has not been observed in laboratory experiments at LLNL, it will be assumed that the primary mode of LC is crevice corrosion. This APC model will be applied to each patch in the WAPDEG simulation. To the 


\section{CHECK COPY}

extent possible, uncertainty will bé estimated from available data.

\subsubsection{Corrosion Rates Based Upon Electrochemical Measurements}

The corrosion potential depends upon environment, and is illustrated by Figure 6-8. The local minima in current observed at the corrosion potential (circled) can be interpreted in terms of a penetration rate, provided that the current is due to dissolution. The corrosion (penetration) rate of an alloy can be calculated from the corrosion current density with the following formula (Jones 1996):

$$
\frac{d p}{d t}=\frac{i_{\text {cnar }}}{\rho_{\text {alloy }} n_{\text {alloy }} F}
$$

where $p$ is the penetration depth, $t$ is time, $i_{\text {corr }}$ is the corrosion current density, $\rho_{\text {alloy }}$ is the density of the alloy, assumed to be approximately $4.54 \mathrm{~g} \mathrm{~cm}^{-3}, n_{\text {alloy }}$, is number of gram equivalents per gram of alloy, and $F$ is Faraday's constant. The value of $n_{\text {alloy }}$ can kie calculated with the following formula:

$n_{\text {alloy }}=\sum_{j}\left(\frac{f_{j} n_{j}}{a_{j}}\right)$

where $f_{j}$ is the mass fraction of the $\mathrm{j}$-th alloying element in the material, $n_{j}$ are the number of electrons involved in the anodic dissolution process, which is assumed to be congruent, and $a_{j}$ is the atomic weight of the $j$-th alloying element. These equations have been used to calculate the penetration rate for $\mathrm{Ti}$ Gr 7 as a function of corrosion current density. The results of these calculations are shown in Tables 6-4 and 6-5. The penetration rate for this material is linearly proportional to current density and is estimated to be between 11.55 and 11.51 microns per year at one microamp per square centimeter. If the corrosion current is due to oxidation rather than dissolution, the penetration corresponds to the thickness of titanium metal converted to oxide. From Figures 6-1 through 6-5, it can be seen that typical values of the corrosion current density range from approximately $10^{-9} \mathrm{~A} \mathrm{~cm}^{-2}$ to approximately $10^{-8} \mathrm{~A} \mathrm{~cm}^{-2}\left(10^{-3}\right.$ to $\left.10^{-2} \mu \mathrm{A} \mathrm{cm}^{-2}\right)$. This corresponds to penetration (or oxidation) rates that range from 0.01 to 0.1 microns per year (10 to 100 nanometers per year). This is in reasonable agreement with the rates given in Section 6.5.2.

The corrosion and passive currents from cyclic polarization measurements in SDW, SCW, SAW and SSW are summarized in Figures 6-10 through 6-13. In general, it has been found that the current versus temperature data can be represented by one of the following linear regression equations. The linear and polynomial forms are both represented by:

$y=b_{0}+b_{1} x+b_{2} x^{2}$

The exponential form is represented by: 


\section{CHECK COPY}

$\ln y=\ln b_{0}+b_{1} \ln x$

where $y$ is the passive current $(\mathrm{A})$ and $x$ is the temperature $\left({ }^{\circ} \mathrm{C}\right)$. This can be rewritten as:

$y=b_{0} \times(x)^{b_{1}}$

Since the exposed area in these measurements is approximately $0.96 \mathrm{~cm}^{2}$, the current density can be obtained by dividing the area into the current. The coefficients based upon the correlation of data for SDW, SCW, SAW and SSW are summarized in Table 6-6. The current density is converted to a corrosion rate based upon the information in Tables 6-4 and 6-5. The corrosion current density should be used as the basis of any corrosion rate estimate. This is the rate that should be experienced at the open circuit corrosion potential. Under actual conditions, even with significant anodic shifts in the corrosion potential, passive current densities are not expected. Clearly, if the passive current density is experienced under repository conditions, unacceptable rates of penetration would be experienced. 
Table 6 - 4. Conversion of Current Density to Corrosion (Penetration) Rate [DTN \# ].

\begin{tabular}{|l|l|c|c|}
\hline & & Value at Low $\mathrm{f}_{\mathrm{f}}$ & Value at High $\mathrm{f}_{\mathrm{i}}$ \\
\hline Faraday Constant & C equiv-1 & $9.648460 \mathrm{E}+04$ & $9.648460 \mathrm{E}+04$ \\
\hline Assumed Current Density & $\mathrm{A} \mathrm{cm}$ & $1.000000 \mathrm{E}-06$ & $1.000000 \mathrm{E}-06$ \\
\hline Assumed Mass Density & $\mathrm{gm} \mathrm{\textrm {cm } ^ { 2 }}$ & $4.540000 \mathrm{E}+00$ & $4.540000 \mathrm{E}+00$ \\
\hline Total $\left(\mathrm{f}_{\mathrm{j}} \mathrm{n}_{\mathrm{j}} / \mathrm{a}_{\mathrm{j}}\right) / 100$ & & $6.233572 \mathrm{E}-02$ & $6.257576 \mathrm{E}-02$ \\
\hline $\mathrm{dp} / \mathrm{dt}$ & $\mathrm{cm} \mathrm{sec}^{-1}$ & $3.662260 \mathrm{E}-11$ & $3.648212 \mathrm{E}-11$ \\
\hline $\mathrm{dp} / \mathrm{dt}$ & microns per year & $1.154930 \mathrm{E}+01$ & $1.150500 \mathrm{E}+01$ \\
\hline
\end{tabular}

Table 6 - 5. Conversion of Current Density to Corrosion (Penetration) Rate [DTN \# ].

\begin{tabular}{|c|c|c|c|c|c|c|c|c|}
\hline & $a_{j}$ & $n_{j}$ & $n_{j}$ & $n_{j}$ & $f_{j}$ & $f_{j}$ & $\left(f_{j} n_{j} / a_{j}\right) / 100$ & $\left(f_{j} n_{j} / a_{j}\right) / 100$ \\
\hline & & & & & $W t . \%$ & Wt. \% & & High \\
\hline $\mathrm{C}$ & 12.011 & 2 & 4 & 4 & 0.000 & 0.080 & $0.000000 \mathrm{E}+00$ & $2.664224 \mathrm{E}-04$ \\
\hline $\mathrm{Ni}$ & 58.69 & 2 & 3 & 2 & 0.000 & 0.000 & $0.000000 \mathrm{E}+00$ & $0.000000 \mathrm{E}+00$ \\
\hline $\mathrm{Cr}$ & 51.9969 & 3 & 6 & 3 & 0.000 & 0.000 & $0.000000 \mathrm{E}+00$ & $0.000000 \mathrm{E}+00$ \\
\hline $\mathrm{Fe}$ & 95.94 & 3 & 6 & 3 & 0.000 & 0.000 & $0.000000 \mathrm{E}+00$ & $0.000000 \mathrm{E}+00$ \\
\hline $\mathrm{Cu}$ & 55.847 & 2 & 3 & 2 & 0.300 & 0.000 & $1.074364 \mathrm{E}-04$ & $0.000000 \mathrm{E}+00$ \\
\hline $\mathrm{P}$ & 30.973762 & 3 & 5 & 5 & 0.000 & 0.000 & $0.000000 \mathrm{E}+00$ & $0.000000 \mathrm{E}+00$ \\
\hline $\mathrm{Si}$ & 28.0855 & 4 & 4 & 4 & 0.000 & 0.000 & $0.000000 \mathrm{E}+00$ & $0.000000 \mathrm{E}+00$ \\
\hline $\mathrm{S}$ & 32.066 & 2 & 6 & 6 & 0.000 & 0.000 & $0.000000 \mathrm{E}+00$ & $0.000000 \mathrm{E}+00$ \\
\hline $\mathrm{Mn}$ & 54.93805 & 2 & 2 & 2 & 0.000 & 0.000 & $0.000000 \mathrm{E}+00$ & $0.000000 \mathrm{E}+00$ \\
\hline $\mathrm{W}$ & 183.85 & 2 & 6 & 6 & 0.000 & 0.000 & $0.000000 \mathrm{E}+00$ & $0.000000 \mathrm{E}+00$ \\
\hline $\mathrm{Co}$ & 58.9332 & 2 & 3 & 2 & 0.000 & 0.000 & $0.000000 \mathrm{E}+00$ & $0.000000 \mathrm{E}+00$ \\
\hline $\mathrm{V}$ & 50.9415 & 2 & 3 & 3 & 0.000 & 0.000 & $0.000000 \mathrm{E}+00$ & $0.000000 \mathrm{E}+00$ \\
\hline $\mathrm{Ti}$ & 47.88 & 2 & 3 & 3 & 99.280 & 99.370 & $6.220551 \mathrm{E}-02$ & $6.226190 \mathrm{E}-02$ \\
\hline $\mathrm{Pd}$ & 105.42 & 2 & 2 & 2 & 0.120 & 0.250 & $2.276608 \mathrm{E}-05$ & $4.742933 \mathrm{E}-05$ \\
\hline Other & 1 & 0 & 0 & 0 & 0.300 & 0.300 & $0.000000 \mathrm{E}+00$ & $0.000000 \mathrm{E}+00$ \\
\hline Total & & & & & 100.000 & 100.000 & $6.233572 \mathrm{E}-02$ & $6.257576 \mathrm{E}-02$ \\
\hline
\end{tabular}




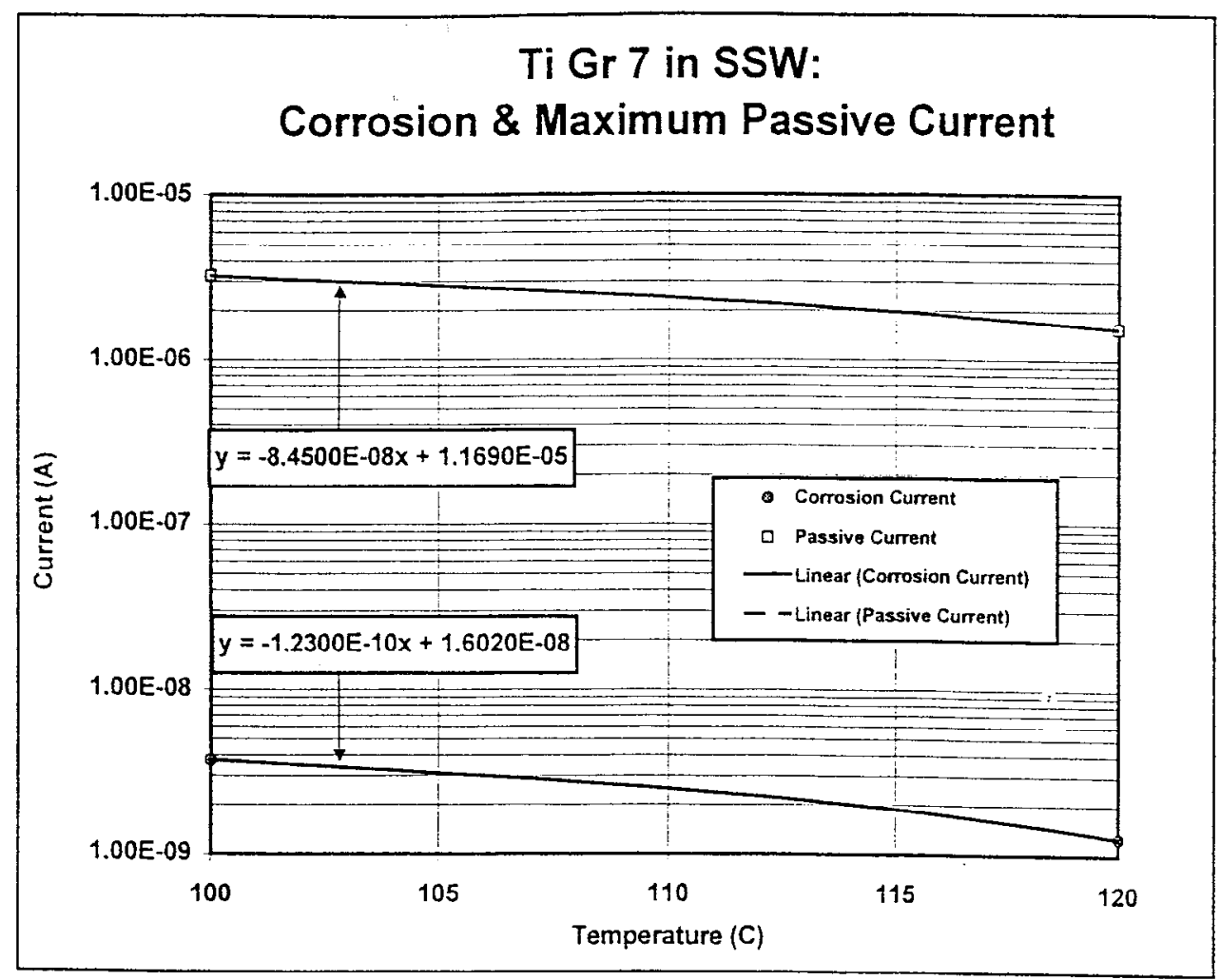

Figure 6 - 10. Corrosion \& Passive Currents for Titanium Grade 7 in SSW [DTN \# ].

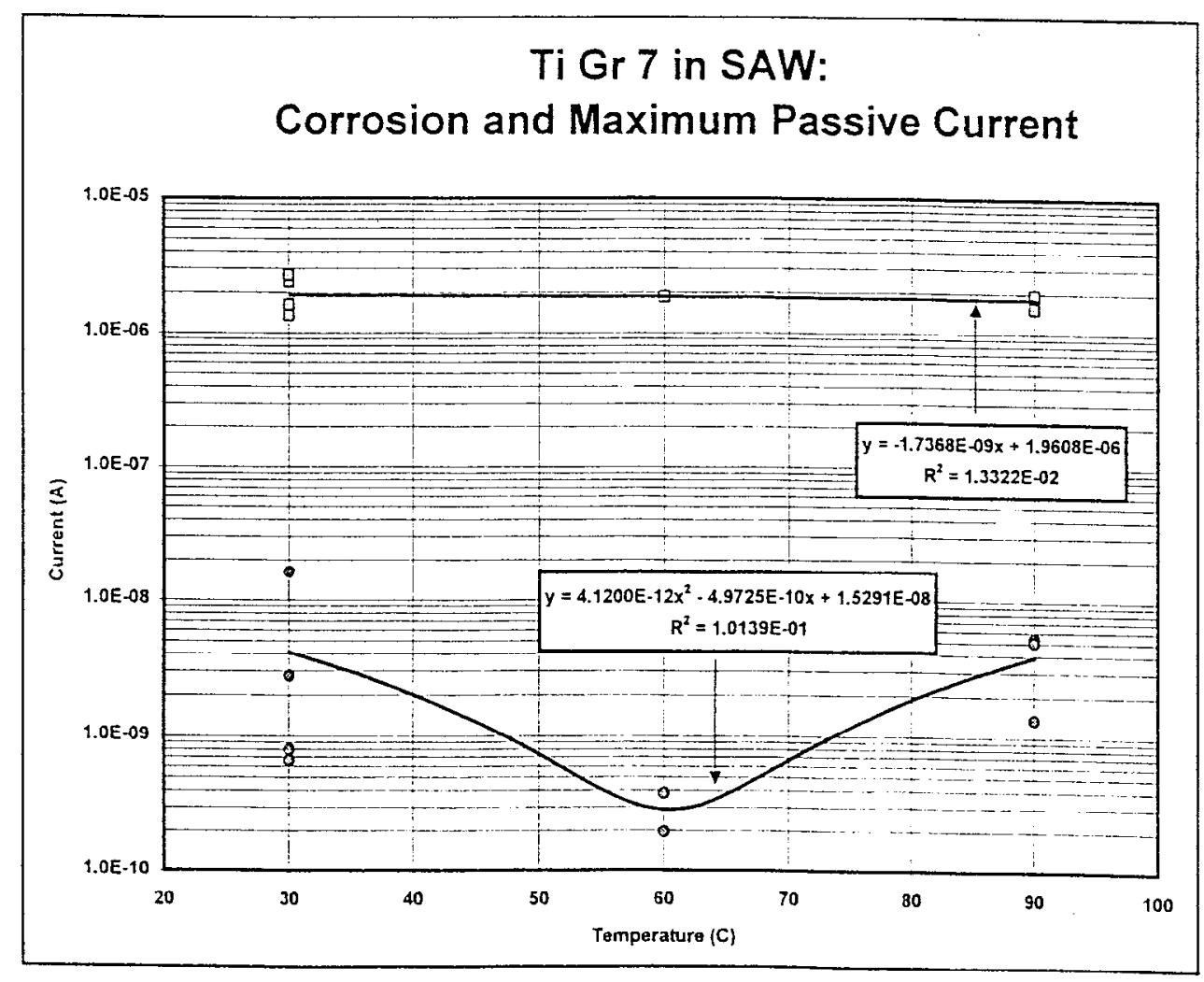

Figure 6 - 11. Corrosion \& Passive Currents for Titanium Grade 7 in SAW [DTN \# ]. 


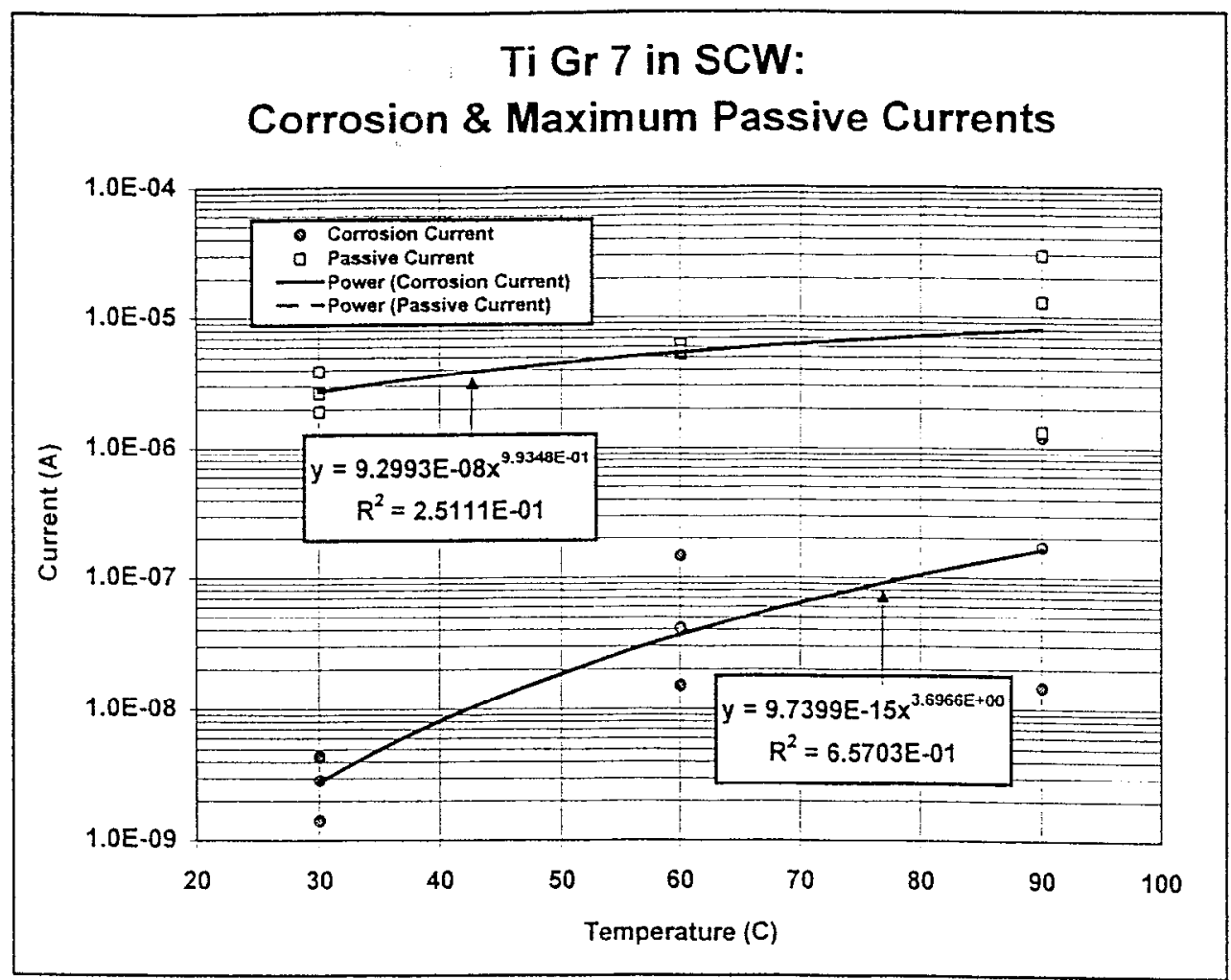

Figure 6 - 12. Corrosion \& Passive Currents for Titanium Grade 7 in SCW [DTN \# ].

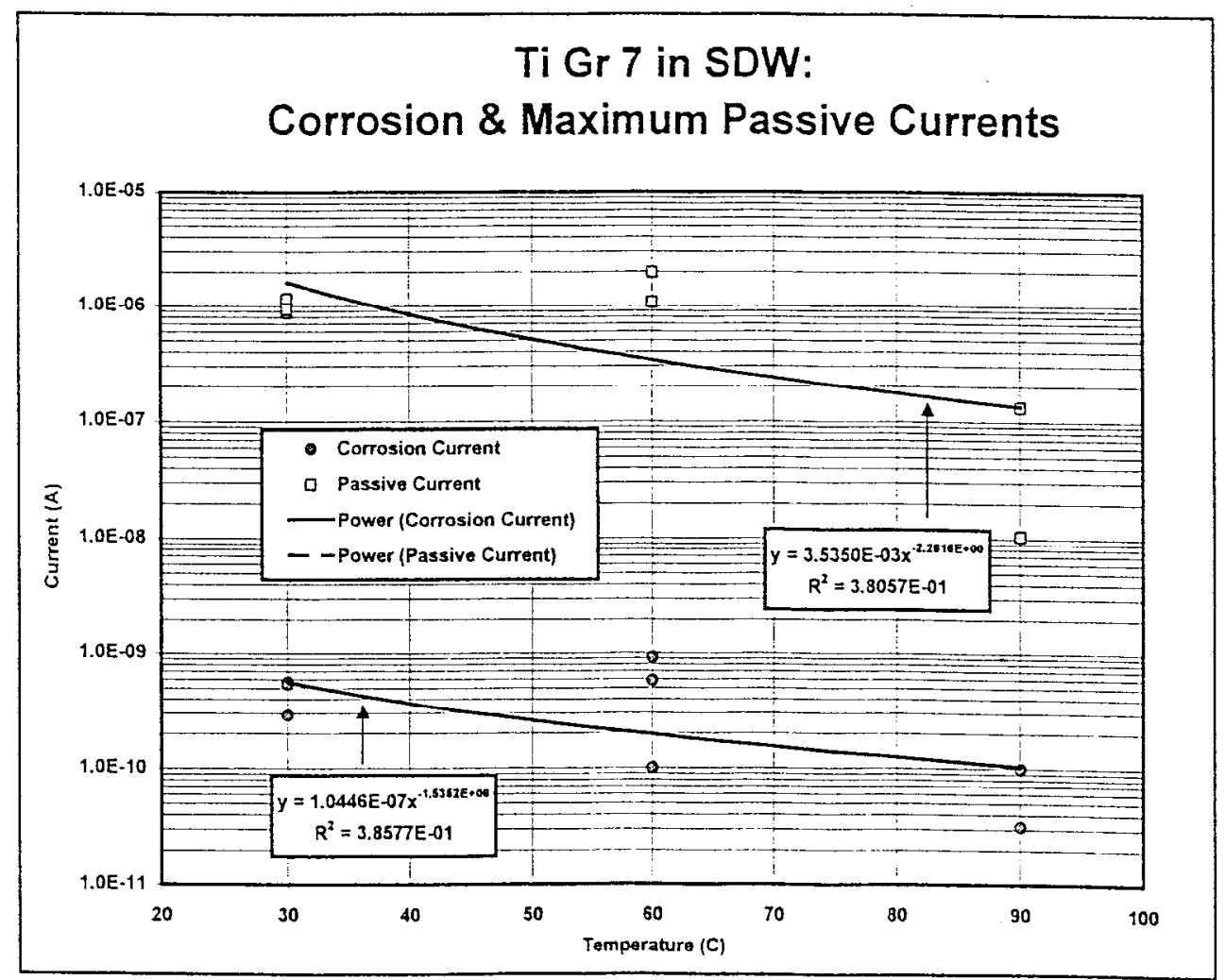

Figure 6 - 13. Corrosion \& Passive Currents for Titanium Grade 7 in SDW [DTN \#]. 
CHECK COPY

Table 6 - 6. Coefficients for Regression Equations Used to Represent Corrosion and Passive Current Data [DTN \#].

\begin{tabular}{|c|c|c|c|c|c|c|c|}
\hline Medium & Current & $\begin{array}{c}\text { Corresponding } \\
\text { Potential }\end{array}$ & $\begin{array}{c}\text { Correlation } \\
\text { Type }\end{array}$ & $\mathbf{b}_{0}$ & $b_{1}$ & $b_{2}$ & $\mathrm{R}^{2}$ \\
\hline SDW & Corrosion & $E_{\text {corr }}$ & Power & $1.0446 \mathrm{E}-07$ & -1.5352 & & 0.3858 \\
\hline SDW & Passive & $E_{\text {critical }}$ & Power & $3.5350 \mathrm{E}-03$ & -2.2616 & & 0.3806 \\
\hline SCW & Corrosion & $E_{\text {corr }}$ & Power & $9.7399 \mathrm{E}-15$ & 3.6966 & & 0.6570 \\
\hline SCW & Passive & $E_{\text {critical }}$ & Power & $9.2993 \mathrm{E}-08$ & 0.9935 & & 0.2258 \\
\hline SAW & Corrosion & $E_{\text {orr }}$ & Polynomial & $1.5291 \mathrm{E}-08$ & $-4.9725 \mathrm{E}-10$ & $4.1200 \mathrm{E}-12$ & 01014 \\
\hline SAW & Passive & $E_{\text {critlcal }}$ & Linear & $1.9608 \mathrm{E}-06$ & $-1.7368 \mathrm{E}-09$ & & 0.0133 \\
\hline SSW & Corrosion & $E_{\text {cor }}$ & Linear & $-12300 \mathrm{E}-10$ & $16020 \mathrm{~F}-08$ & & None \\
\hline SSW & Passive & $E_{\text {crittcal }}$ & Linear & $1.1690 \mathrm{E}-05$ & -8.4500 E- 08 & & None \\
\hline
\end{tabular}




\section{CHECK COPY}

\subsubsection{Corrosion Rates Based Upon Weight Loss Measurements}

It will be assumed that the general corrosion rates of $\mathrm{Ti}$ Gr 16 measured in the Long Term Corrosion Test Facility (LTCTF) are representative of those for Ti Gr 7. Testing includes a wide range of plausible generic test media, including Simulated Dilute Water (SDW), Simulated Concentrated Water (SCW) and Simulated Acid Water (SAW). The SCW test medium is three orders-of-magnitude $(1000 \mathrm{X})$ more concentrated than $\mathrm{J}-13$ well water and is slightly alkaline $(\mathrm{pH} \sim 8)$. The SAW test medium is three orders-of-magnitude $(1000 \mathrm{X})$ more concentrated than J13 well water and is acidic $(\mathrm{pH} 2.7)$. Two temperature levels $\left(60\right.$ and $\left.90^{\circ} \mathrm{C}\right)$ are included in this qualified (Q) testing program. It will be further assumed that all drip shields undergo general corrosion at a constant rate corresponding to the maximum observed value. The maximum observed rate, which is much less than 1 micron per year, clearly indicates that the life of the DS will not be limited by general corrosion. It will also be assumed that the corrosion rate is constant, and does not decay with time. Less conservative corrosion models assume that the rate decays with time.

The Long Term Corrosion Test Facility (LTCTF) appears to be the most complete source of corrosion data for Ti Gr 16 in environments relevant to the proposed high-level waste repository at Yucca Mountain. This facility is equipped with an array of nearly cubic fiberglass tanks. Each tank has a total volume of -2000 liters and is filled with $\sim 1000$ liters of aqueous test solution. The solution in a particular tank is controlled at either 60 or $90^{\circ} \mathrm{C}$, covered with a blanket of air flowing at approximately $150 \mathrm{~cm}^{3} \mathrm{~min}^{-1}$, and agitated. The test environments used in the LTCTF are referred to as: Simulated Dilute Water (SDW); Simulated Concentrated Water (SCW); Simulated Acidic Concentrated Water (SAW); and Simulated Cement-Modified Water (SCMW). The descriptions and compositions of three of these solutions are summarized in Tables 6-3 and 6-4. Four generic types of samples, U-bends, crevices, weight loss samples and galvanic couples, are mounted on insulating racks and placed in the tanks. Approximately half of the samples are submersed, half are in the saturated vapor above the aqueous phase, and a limited number at the water line. It is important to note that condensed water is present on specimens located in the saturated vapor.

As previously discussed, general corrosion measurments have been based upon ASTM G 1-81 (ASTM 1989b). The general corrosion (or penetration) rate of an alloy can be calculated from weight loss data as follows with the following general formula:

Corrosion Rate $=\frac{(K \times W)}{(A \times T \times D)}$

where $K$ is a constant, $T$ is the time of exposure in hours, $A$ is the exposed area of the sample in square centimeters, $W$ is the mass loss in grams, and $D$ is the density in grams per cubic centimeter. The value of $K$ used for the LTCTF data was $8.76 \times 10^{7}$ microns per year. This formula for corrosion rate can be rewritten in the following form:

$$
\frac{d p}{d t}=\frac{w}{\rho \times t} \frac{1}{[2(a \times b)+2(b \times c)+2(a \times c)]}
$$




\section{CHECK COPY}

\subsubsection{Uncertainty in Weight Loss Measurements}

The best representation of the uncertainty in the measured corrosion rate of Ti Gr 16 in the LTCTF appears to be normal distribution. It is assumed that the measured corrosion rate is a random variable with a mean $\mu$ and a standard deviation $\sigma$. As discussed by Burr (1974), the density function is:

$f(y)=\frac{\exp \left[-\frac{(y-\mu)^{2}}{2 \sigma^{2}}\right]}{\sigma \sqrt{2 \pi}} \quad( \pm \infty)$

The properties of this function are well known. First, the curve is symmetrical about the mean value, and the area underneath the curve is one. The following standard areas fall between the specified low and high limits:

Table 6 - 7. Standard Areas Under Density Function for Normal Distribution

\begin{tabular}{|c|c|c|}
\hline Low Limit & High Limit & Area Under Curve \\
\hline$\mu-1 \times \sigma$ & $\mu+1 \times \sigma$ & 0.6827 \\
\hline$\mu-2 \times \sigma$ & $\mu+2 \times \sigma$ & 0.9545 \\
\hline$\mu-3 \times \sigma$ & $\mu+3 \times \sigma$ & 0.9973 \\
\hline$\mu-1.960 \times \sigma$ & $\mu+1.960 \times \sigma$ & 0.9500 \\
\hline$\mu-2.576 \times \sigma$ & $\mu+2.576 \times \sigma$ & 0.9900 \\
\hline
\end{tabular}

The cumulative probability is obtained by integration of the density function. Figures 6-18 and 6-20 represcnt the cumulative probabilities for general corrosion rates measured in the LTCTF, based upon weight loss and crevice samples, respectively. The mean and standard deviation of these curves are first determined by inspection, with the results given in Tables 6-8 and 6-9.

Table 6 - 8. Mean and Standard Deviation of General Corrosion Rates - Weight Loss

\begin{tabular}{|c|c|c|}
\hline Parameter & $\begin{array}{l}\text { All Data } \\
\left(\mathrm{nm} \mathrm{y}^{-1}\right)\end{array}$ & $\begin{array}{l}\text { No Outlier } \\
\left(n \mathrm{y} \mathrm{y}^{-1}\right)\end{array}$ \\
\hline$\mu$ & -143.80 & -16.51 \\
\hline$\sigma$ & +391.90 & +72.70 \\
\hline
\end{tabular}

Table 6 - 9. Mean and Standard Deviation of General Corrosion Rates - Crevice Samples

\begin{tabular}{|c|c|c|}
\hline Parameter & $\begin{array}{c}\text { All Data } \\
\left(\mathrm{nm} \mathrm{y}^{-1}\right)\end{array}$ & $\begin{array}{c}\text { No Outlier } \\
\left(\mathrm{nm} \mathrm{y}^{-1}\right)\end{array}$ \\
\hline$\mu$ & -11.83 & \\
\hline$\sigma$ & +93.25 & \\
\hline
\end{tabular}

The distributions of corrosion rates are centered around negative mean values. The negative corrosion rates that are significant correspond to cases where the samples actually appear to have gained weight during exposure, due to oxide growth or the formation of silica deposits. To substantiate these interpretations, atomic force microscopy has been used to inspect a number of samples removed from the LTCTF. 


\section{CHECK COPY}

\subsubsection{Error Analysis for Weight Loss Measurements}

The general method used in the formal error analysis is now presented. Consider the dependent variable $y$ defined by the following generic function:

$y=f\left(x_{1}, x_{2}, x_{3}, x_{4} \cdots x_{n}\right)$

where $x_{i}$ is the $i^{\text {th }}$ independent variable. The total derivative of $y$ is then defined as:

$d y=\frac{\partial y}{\partial x_{1}} d x_{1}+\frac{\partial y}{\partial x_{2}} d x_{2}+\frac{\partial y}{\partial x_{3}} d x_{3}+\frac{\partial y}{\partial x_{4}} d x_{4}+\cdots+\frac{\partial y}{\partial x_{n}} d x_{n}$

Based upon this definition, the maximum error in y can then be defined as:

$\Delta y=\left|\frac{\partial y}{\partial x_{1}} \Delta x_{1}\right|+\left|\frac{\partial y}{\partial x_{2}} \Delta x_{2}\right|+\left|\frac{\partial y}{\partial x_{3}} \Delta x_{3}\right|+\left|\frac{\partial y}{\partial x_{4}} \Delta x_{4}\right|+\cdots+\left|\frac{\partial y}{\partial x_{n}} \Delta x_{n}\right|$

where $\Delta x_{i}$ is the error in the $i^{t h}$ independent variable. Let the dependent variable y be the general corrosion rate measured in the LTCTF:

$y=\frac{d p}{d t}=\frac{w}{\rho \times t} \frac{1}{[2(a \times b)+2(b \times c)+2(a \times c)]}$

The total derivative of the corroison rate is:

$d y=\frac{\partial y}{\partial w} d w+\frac{\partial y}{\partial \rho} d \rho+\frac{\partial y}{\partial t} d t+\frac{\partial y}{\partial a} d a+\frac{\partial y}{\partial b} d b+\frac{\partial y}{\partial c} d c$

The maximum error in the corrosion rate is:

$\Delta y=\left|\frac{\partial y}{\partial w} \Delta w\right|+\left|\frac{\partial y}{\partial \rho} \Delta \rho\right|+\left|\frac{\partial y}{\partial t} \Delta t\right|+\left|\frac{\partial y}{\partial a} \Delta a\right|+\left|\frac{\partial y}{\partial b} \Delta b\right|+\left|\frac{\partial y}{\partial c} \Delta c\right|$

The partial derivates are:

$\frac{\partial y}{\partial w}=\frac{1}{\rho \times t}[2(a \times b)+2(b \times c)+2(a \times c)]$
$\frac{\partial y}{\partial \rho}=\frac{w}{\rho^{2} \times t} \cdot \frac{1}{[2(a \times b)+2(b \times c)+2(a \times c)]}$ 


\section{CHECK COPY}

$$
\begin{aligned}
& \frac{\partial y}{\partial t}=\frac{w}{\rho \times t^{2}} \frac{1}{[2(a \times b)+2(b \times c)+2(a \times c)]} \\
& \frac{\partial y}{\partial a}=\frac{w}{\rho \times t} \frac{[2 b+2 c]}{[2(a \times b)+2(b \times c)+2(a \times c)]^{2}} \\
& \frac{\partial y}{\partial b}=\frac{w}{\rho \times t} \frac{[2 a+2 c]}{[2(a \times b)+2(b \times c)+2(a \times c)]^{2}} \\
& \frac{\partial y}{\partial c}=\frac{w}{\rho \times t} \frac{[2 a+2 b]}{[2(a \times b)+2(b \times c)+2(a \times c)]^{2}}
\end{aligned}
$$

The maximum error in the corrosion rate is estimated by calculating numeric values of the partial derivatives from expected values of the independent variables, multiplication of each partial derivative by the comesponding error in independent variable ( $\Delta w, \Delta \rho, \Delta t, \Delta a, \Delta b$ and $\Delta c)$, and summation of the resulting products. The error based upon this method is shown in Tables 6-10 through 6-14. From the estimated errors given in Table 6-11, it is concluded that the typical uncertainty observed in weight loss and dimensional measurements prevent determination of corrosion rates less than 46 nanometers per year (crevice sample worst case). This estimate of error is believed to correspond to about one standard deviation $(1 \sigma)$. Therefore, any measured corrosion rate less than 184 nanometers per year $(4 \sigma)$ will not be distinguishable from measurement error.

General corrosion rates determined from measurements of weight loss in the LTCTF are shown in Figures 6-15 and 6-16. The LTCTF and results from that facility are described in detail previous publications by the Project (Estill 1998). The maximum rates shown in Figure 6-16 appear to be less than about 350 nanometers per year, slightly greater than the estimated $4 \sigma$ value. Any rate less than $350 \mathrm{~nm}$ per year guarantees that the DS (wall thickness of $2 \mathrm{~cm}$ ) will not fail by general corrosion. Note that the impact of the hole in the crevice samples on the error analysis was believed to be relatively small, and therefore neglected.

Table 6 - 10. Summary of Error Analysis for Corrosion Rates Based Upon Weight Loss Measurements

\begin{tabular}{|c|c|c|c|c|c|}
\hline & Assumed Wt. Loss & & $0.0001 \mathrm{gm}$ & $0.0010 \mathrm{gm}$ & $\mathbf{0 . 0 1 0 0 \mathrm { gm }}$ \\
\hline & & & $\Delta \mathrm{y}$ & $\Delta \mathrm{y}$ & $\Delta \mathrm{y}$ \\
\hline Case & Sample Configuration & Exposure Time & $\mathrm{nm} \mathrm{\textrm {y } ^ { - 1 }}$ & $\mathrm{nm} \mathrm{y}^{-\mathrm{T}}$ & $\mathrm{nm}^{-1}$ \\
\hline 1 & Crevice & 6 month & 23.64 & 25.72 & 46.47 \\
\hline 2 & Weight Loss & 6 month & 44.89 & 48.94 & 89.41 \\
\hline 3 & Crevice & 12 month & 11.58 & 12.50 & 21.70 \\
\hline 4 & Weight Loss & 12 month & 22.00 & 23.79 & 41.78 \\
\hline
\end{tabular}




\section{CHECK COPY}

Table 6 - 11. Error Analysis for LTCTF Corrosion Rates - Definitions

\begin{tabular}{|c|c|c|}
\hline Parameter & Parameter Cefinition & Units \\
\hline W & Weight loss & $g m$ \\
\hline$\rho$ & Density & $\mathrm{gm} \mathrm{cm}^{-3}$ \\
\hline$T$ & Exposure time & $\mathrm{hr}$ \\
\hline$A$ & Length & in \\
\hline$B$ & Width & in. \\
\hline $\mathrm{C}$ & Thickness & in \\
\hline$A$ & Length & $\mathrm{cm}$ \\
\hline $\bar{B}$ & Width & $\mathrm{cm}$ \\
\hline$\overline{\mathrm{C}}$ & Thickness & $\mathrm{cm}$ \\
\hline$\partial y / \partial w$ & Partial derivative or rate with respect to weight loss & $\mathrm{cm} \mathrm{gm}^{-1} \mathrm{~h}^{-1}$ \\
\hline$\partial y / \partial \rho$ & Partial derivative of rate with respect to density & $\mathrm{cm}^{4} \mathrm{gm}^{-1} \mathrm{~h}^{-1}$ \\
\hline$\hat{\partial y} / \partial \mathrm{t}$ & Partial derivative of rate with respect to exposure time & $\mathrm{cm} \mathrm{h}^{-2}$ \\
\hline$\partial y / \partial े a$ & Partial derivative of rate with respect to length & $h^{-1}$ \\
\hline$\partial y / d b$ & Partial derivative of rate with respect to width & $h^{-1}$ \\
\hline$\partial y / \partial \mathrm{c}$ & Partial derivative of rate with respect to thickness & $h^{-1}$ \\
\hline$\Delta \mathrm{w}$ & Error in weight loss & $g m$ \\
\hline$\Delta \rho$ & Error in density & $9 \mathrm{gcm}^{-3}$ \\
\hline$\Delta t$ & Error in exposure time & hr \\
\hline$\Delta \mathrm{a}$ & Error in length & $\mathrm{cm}$ \\
\hline$\Delta b$ & Error in width & $\mathrm{cm}$ \\
\hline$\Delta \mathrm{c}$ & Error in thickness & $\mathrm{cm}$ \\
\hline$(\partial y / \partial w) \times(\Delta w)$ & Weight loss product & $\mathrm{cm}$ \\
\hline$(\partial y / \partial \rho) \times(\Delta \rho)$ & Density product & $\mathrm{cm}$ \\
\hline$(\partial y / \partial t) \times(\Delta t)$ & Exposure time product & $\mathrm{cm}$ \\
\hline$(\partial y / \partial a) \times(\Delta a)$ & Length product & $\mathrm{cm}$ \\
\hline$(\partial y / d b) \times(\Delta b)$ & Width product & $\mathrm{cm}$ \\
\hline$(\partial y / \partial c) \times(\Delta c)$ & Thickness product & $\mathrm{cm}$ \\
\hline$\Delta y$ & Sum of all products & $\mathrm{cm} \mathrm{h}^{-1}$ \\
\hline$\Delta y$ & Sum of all products & $\mu m y^{-1}$ \\
\hline$\Delta y$ & Sum of all products & $n m y^{-1}$ \\
\hline
\end{tabular}


Table 6 - 12. Error Analysis for'LTCTF Corrosion Rates - Assume Weight Loss of 0.0001 Grams

\begin{tabular}{|c|c|c|c|c|}
\hline Parameter & Crevice 6 mo. & Wt. Loss 6 mo. & Crevice $12 \mathrm{mo}$. & Wt. Loss 12 mo. \\
\hline & & & & \\
\hline$w$ & 0.0001 & 0.0001 & 0.0001 & 0.0001 \\
\hline$\rho$ & 4.52 & 4.52 & 4.52 & 4.52 \\
\hline $\mathrm{t}$ & 4296 & 4296 & 8760 & 8760 \\
\hline $\bar{a}$ & 2.0000 & 2.0000 & 2.0000 & 2.0000 \\
\hline$b$ & 2.0000 & 1.0000 & 2.0000 & 1.0000 \\
\hline $\mathrm{c}$ & 0.1200 & 0.1200 & 0.1200 & 0.1200 \\
\hline$a$ & 5.0800 & 5.0800 & 5.0800 & 5.0800 \\
\hline $\mathrm{b}$ & 5.0800 & 2.5400 & 5.0800 & 2.5400 \\
\hline $\mathrm{c}$ & 0.3048 & 0.3048 & 0.3048 & 0.3048 \\
\hline & & & & \\
\hline$\partial y / \partial w$ & $8.9089 \mathrm{E}-07$ & $1.6912 \mathrm{E}-06$ & $4.3690 \mathrm{E}-07$ & $8.2937 \mathrm{E}-07$ \\
\hline$\partial y / \partial \rho$ & $1.9710 \mathrm{E}-11$ & $3.74 \because 5 \mathrm{E}-11$ & $9.6659 \mathrm{E}-12$ & $1.8349 E-11$ \\
\hline$\partial \mathrm{y} / \partial \mathrm{t}$ & $2.0738 \mathrm{E}-14$ & $3.9366 \mathrm{E}-14$ & $4.9874 \mathrm{E}-15$ & $9.4677 \mathrm{E}-15$ \\
\hline$\partial y / \partial a$ & $1.6598 \mathrm{E}-11$ & $3.1598 \mathrm{E}-11$ & $8.1397 E-12$ & 1.5496E-11 \\
\hline$\partial y / d b$ & $1.6598 \mathrm{E}-11$ & $5.9811 \mathrm{E}-11$ & $8.1397 \mathrm{E}-12$ & $2.9332 \mathrm{E}-11$ \\
\hline$\partial y / \partial c$ & $3.1316 \mathrm{E}-11$ & $8.4638 \mathrm{E}-11$ & $1.5358 \mathrm{E}-11$ & $4.1507 \mathrm{E}-11$ \\
\hline & & & & \\
\hline$\Delta \mathrm{w}$ & 0.0003 & 0.0003 & 0.0003 & 0.0003 \\
\hline$\Delta \rho$ & 0.1 & 0.1 & 0.1 & 0.1 \\
\hline$\Delta \mathrm{t}$ & 24 & 24 & 24 & 24 \\
\hline$\Lambda \mathrm{a}$ & 0.00254 & 0.00254 & 0.00254 & 0.00254 \\
\hline$\Delta b$ & 0.00254 & 0.00254 & 0.00254 & 0.00254 \\
\hline$\Delta c$ & 0.00254 & 0.00254 & 0.00254 & 0.00254 \\
\hline & & & & \\
\hline$(\partial y / \partial w) \times(\Delta w)$ & $2.6727 \mathrm{E}-10$ & $5.0735 \mathrm{E}-10$ & $1.3107 \mathrm{E}-10$ & $2.4881 \mathrm{E}-10$ \\
\hline$(\partial y / \partial \rho) \times(\Delta \rho)$ & $1.9710 \mathrm{E}-12$ & $3.7415 \mathrm{E}-12$ & $9.6659 \mathrm{E}-13$ & $1.8349 \mathrm{E}-12$ \\
\hline$(\partial y / \partial t) \times(\Delta t)$ & $4.9770 \mathrm{E}-13$ & $9.4479 \mathrm{E}-13$ & $1.1970 \mathrm{E}-13$ & $2.2722 \mathrm{E}-13$ \\
\hline$(\partial \mathrm{y} / \partial \mathrm{a}) \times(\Delta \mathrm{a})$ & $4.2158 \mathrm{E}-14$ & $8.0259 \mathrm{E}-14$ & $2.0675 \mathrm{E}-14$ & $3.9360 E-14$ \\
\hline$(\partial \mathrm{y} / \mathrm{db}) \times(\Delta \mathrm{b})$ & $4.2158 \mathrm{E}-14$ & $1.5192 \mathrm{E}-13$ & $2.0675 E-14$ & $7.4503 E-14$ \\
\hline$(\partial y / \partial c) \times(\Delta c)$ & $7.9543 \mathrm{E}-14$ & $2.1498 \mathrm{E}-13$ & $3.9009 E-14$ & $1.0543 E-13$ \\
\hline$\Delta y$ & $2.6990 \mathrm{E}-10$ & $5.1249 \mathrm{E}-10$ & $1.3224 \mathrm{E}-10$ & $25109 \mathrm{~F}-10$ \\
\hline$\Delta y$ & $2.3643 \mathrm{E}-02$ & $4.4894 \mathrm{E}-02$ & $1.1584 \mathrm{E}-02$ & $2.1996 \mathrm{E}-02$ \\
\hline$\Delta y$ & $2.3643 E+01$ & $4.4894 E+01$ & $1.1584 \mathrm{E}+01$ & $2.1996 E+01$ \\
\hline & & & & \\
\hline
\end{tabular}




\section{CHECK COPY}

Table 6 - 13. Error Analysis for LTCTF Corrosion Rates - Assume Weight Loss of 0.001 Grams

Table 1

\begin{tabular}{|c|c|c|c|c|}
\hline Parameter & Crevice 6 mo. & Wt. Loss 6 mo. & Crevice 12 mo. & Wt. Loss $12 \mathrm{mo}$. \\
\hline & & & & \\
\hline$w$ & 0.0010 & 0.0010 & 0.0010 & 0.0010 \\
\hline$\rho$ & 4.52 & 4.52 & 4.52 & 4.52 \\
\hline $\mathrm{t}$ & 4296 & 4296 & 8760 & 8760 \\
\hline$a$ & 2.0000 & 2.0000 & 2.0000 & 2.0000 \\
\hline$b$ & 2.0000 & 1.0000 & 2.0000 & 1.0000 \\
\hline C & 0.1200 & 0.1200 & 0.1200 & 0.1200 \\
\hline$a$ & 5.0800 & 5.0800 & 5.0800 & 5.0800 \\
\hline$b$ & 5.0800 & 2.5400 & 5.0800 & 2.5400 \\
\hline C & 0.3048 & 0.3048 & 0.3048 & 0.3048 \\
\hline & & & & \\
\hline$\partial y / \partial w$ & $8.9089 \mathrm{E}-07$ & $1.6912 \mathrm{E}-06$ & $4.3690 \mathrm{E}-07$ & 8.2937E-07 \\
\hline$\partial y / \partial \rho$ & $1.9710 \mathrm{E}-10$ & $3.7415 \mathrm{E}-10$ & $9.6659 \mathrm{E}-11$ & $1.8349 \mathrm{E}-10$ \\
\hline$\partial y / \partial t$ & $2.0738 \mathrm{E}-13$ & $3.9366 \mathrm{E}-13$ & $4.9874 \mathrm{E}-14$ & $9.4677 E-14$ \\
\hline$\partial y / \partial a$ & $1.6598 \mathrm{E}-10$ & $3.1598 \mathrm{E}-10$ & $8.1397 \mathrm{E}-11$ & $1.5496 \mathrm{E}-10$ \\
\hline$\partial y / d b$ & $1.6598 E-10$ & $5.9811 \mathrm{E}-10$ & $8.1397 \mathrm{E}-11$ & $2.9332 \mathrm{E}-10$ \\
\hline$\partial y / \bar{c}$ & $3.1316 \mathrm{E}-10$ & $8.4638 \mathrm{E}-10$ & $1.5358 \mathrm{E}-10$ & $4.1507 \mathrm{E}-10$ \\
\hline$\Delta w$ & 0.0003 & 0.0003 & 0.0003 & 0.0003 \\
\hline$\Delta \rho$ & 0.1 & 0.1 & 0.1 & 0.1 \\
\hline$\Delta \mathrm{t}$ & 24 & 24 & 24 & 24 \\
\hline$\Delta \mathrm{a}$ & 0.00254 & 0.00254 & 0.00254 & 0.00254 \\
\hline$\Delta b$ & 0.00254 & 0.00254 & 0.00254 & 0.00254 \\
\hline$\Delta \mathrm{C}$ & 0.00254 & 0.00254 & 0.00254 & 0.00254 \\
\hline$(\partial y / \partial w) \times(\Delta w)$ & $2.6727 \mathrm{E}-10$ & $5.0735 \mathrm{E}-10$ & $1.3107 \mathrm{E}-10$ & $2.4881 E-10$ \\
\hline$(\partial y / \partial \rho) \times(\Delta \rho)$ & $1.9710 \mathrm{E}-11$ & $3.7415 \mathrm{E}-11$ & $9.6659 \mathrm{E}-12$ & $1.8349 \mathrm{E}-11$ \\
\hline$(\partial \mathrm{y} / \partial \mathrm{t}) \times(\Delta \mathrm{t})$ & $4.9770 \mathrm{E}-12$ & $9.4479 \mathrm{E}-12$ & $1.1970 \mathrm{E}-12$ & $2.2722 \mathrm{E}-12$ \\
\hline$(\partial \mathrm{y} / \partial \mathrm{a}) \times(\Delta \mathrm{a})$ & $4.2158 \mathrm{E}-13$ & $8.0259 \mathrm{E}-13$ & $2.0675 \mathrm{E}-13$ & $3.9360 \mathrm{E}-13$ \\
\hline$(\partial y / d b) \times(\Delta b)$ & $4.2158 \mathrm{E}-13$ & $1.5192 \mathrm{E}-12$ & $2.0675 \mathrm{E}-13$ & $7.4503 \mathrm{E}-13$ \\
\hline$(\partial \mathrm{y} / \partial \mathrm{c}) \times(\Delta \mathrm{c})$ & $7.9543 E-13$ & $2.1498 \mathrm{E}-12$ & $3.9009 \mathrm{E}-13$ & $1.0543 \mathrm{E}-12$ \\
\hline$\Delta y$ & $2.9359 \mathrm{E}-10$ & $5.5869 \mathrm{E}-10$ & $1.4274 \mathrm{E}-10$ & $2.7162 \mathrm{E}-10$ \\
\hline$\Delta y$ & $2.5719 \mathrm{E}-02$ & $4.8941 \mathrm{E}-02$ & $1.2504 \mathrm{E}-02$ & $2.3794 E-02$ \\
\hline$\Delta y$ & $2.5719 E+01$ & $4.8941 \mathrm{E}+01$ & $1.2504 \mathrm{E}+01$ & $2.3794 E+01$ \\
\hline
\end{tabular}




\section{CHECK COPY}

Table 6 - 14. Error Analysis for LTCTF Corrosion Rates - Assume Weight Loss of 0.01 Grams

\begin{tabular}{|c|c|c|c|c|}
\hline Parameter & Crevice 6 mo. & Wt. Loss 6 mo. & Crevice $12 \mathrm{mo}$. & Wt. Loss 12 mo. \\
\hline $\mathrm{w}$ & 0.0100 & 0.0100 & 0.0100 & 0.0100 \\
\hline$\rho$ & 4.52 & 4.52 & 4.52 & 4.52 \\
\hline$t$ & 4296 & 4296 & 8760 & 8760 \\
\hline$a$ & 2.0000 & 2.0000 & 2.0000 & 2.0000 \\
\hline $\mathrm{b}$ & 2.0000 & 1.0000 & 2.0000 & 1.0000 \\
\hline$c$ & 0.1200 & 0.1200 & 0.1200 & 0.1200 \\
\hline$a$ & 5.0800 & 5.0800 & 5.0800 & 5.0800 \\
\hline$b$ & 5.0800 & 2.5400 & 5.0800 & 2.5400 \\
\hline c & 0.3048 & 0.3048 & 0.3048 & 0.3048 \\
\hline & & & & \\
\hline$\partial y / \partial w$ & $8.9089 \mathrm{E}-07$ & $1.6912 \mathrm{E}-06$ & $4.3690 E-07$ & $8.2937 \mathrm{E}-07$ \\
\hline$\partial y / \partial \rho$ & $1.9710 \mathrm{E}-09$ & $3.7415 \mathrm{E}-09$ & $9.6659 \mathrm{E}-10$ & $1.8349 \mathrm{E}_{\bar{i}} 09$ \\
\hline$\partial y / \partial t$ & $2.0738 \mathrm{E}-12$ & $3.9366 \mathrm{E}-12$ & $4.9874 \mathrm{E}-13$ & $9.4677 E-13$ \\
\hline$\partial y / \partial a$ & $1.6598 \mathrm{E}-09$ & $3.1598 \mathrm{E}-09$ & $8.1397 \mathrm{E}-10$ & $1.5496 \mathrm{E}-09$ \\
\hline$\partial y / d b$ & $1.6598 \mathrm{E}-09$ & $5.9811 \mathrm{E}-09$ & $8.1397 \mathrm{E}-10$ & $2.9332 E-09$ \\
\hline$\partial y / \partial c$ & $3.1316 \mathrm{E}-09$ & $8.4638 \mathrm{E}-09$ & $1.5358 \mathrm{E}-09$ & $4.1507 \mathrm{E}-09$ \\
\hline$\Delta \mathrm{w}$ & 0.0003 & 0.0003 & 0.0003 & 0.0003 \\
\hline$\Delta \rho$ & 0.1 & 0.1 & 0.1 & 0.1 \\
\hline$\Delta \mathrm{t}$ & 24 & 24 & 24 & 24 \\
\hline$\Delta \mathrm{a}$ & 0.00254 & 0.00254 & 0.00254 & 0.00254 \\
\hline$\Delta \mathrm{b}$ & 0.00254 & 0.00254 & 0.00254 & 0.00254 \\
\hline$\Delta c$ & 0.00254 & 0.00254 & 0.00254 & 0.00254 \\
\hline$(\partial y / \partial w) \times(\Delta w)$ & $2.6727 \mathrm{E}-10$ & $5.0735 \mathrm{E}-10$ & $1.3107 E-10$ & $24881 \mathrm{E}-10$ \\
\hline$(\partial y / \partial \rho) \times(\Delta \rho)$ & $1.9710 E-10$ & $3.7415 \mathrm{E}-10$ & $9.6659 E-11$ & $1.8349 \mathrm{E}-10$ \\
\hline$(\partial y / \partial t) \times(\Delta t)$ & $4.9770 \mathrm{E}-11$ & $9.4479 \mathrm{E}-11$ & $1.1970 \mathrm{E}-11$ & $2.2722 \mathrm{E}-11$ \\
\hline$(\partial y / \partial a) \times(\Delta a)$ & $4.2158 \mathrm{E}-12$ & $8.0259 \mathrm{E}-12$ & $2.0675 \mathrm{E}-12$ & $3.9360 E-12$ \\
\hline$(\partial y / d b) \times(\Delta b)$ & $4.2158 \mathrm{E}-12$ & $1.5192 \mathrm{E}-11$ & $2.0675 E-12$ & $7.4503 E-12$ \\
\hline$(\partial \mathrm{y} / \partial \mathrm{c}) \times(\Delta \mathrm{c})$ & $7.9543 E-12$ & $2.1498 \mathrm{E}-11$ & $3.9009 E-12$ & $1.0543 E-11$ \\
\hline$\Delta y$ & $53052 \mathrm{E}-10$ & $10207 \mathrm{E}-09$ & $24773 F_{-10}$ & $47605=10$ \\
\hline$\Delta y$ & $4.6474 \mathrm{E}-02$ & $8.9413 \mathrm{E}-02$ & $2.1702 \mathrm{E}-02$ & $4.1781 \mathrm{E}-02$ \\
\hline$\Delta y$ & $4.6474 \mathrm{E}+01$ & $8.9413 \mathrm{E}+01$ & $2.1702 \mathrm{E}+01$ & $4.1781 E+01$ \\
\hline & & & & \\
\hline
\end{tabular}




\section{CHECK COPY}

\subsection{DISSOLVED OXYGEN IN THE LONG TERM CORROSION TEST FACILITY}

In principle, the corrosion rates observed in the LTCTF should depend upon the concentration of dissolved oxygen. The anodic dissolution of a metal requires a corresponding amount of cathodic reduction. Typically, dissolved oxygen or hydrogen ion is reduced. However, as previously discussed, other reactants such as hydrogen peroxide (due to gamma radiolysis) can also be reduced. Figure 6-24 in the companion AMR on general and localized corrosion of the WPOB (Farmer et al. 1999) shows a comparison of dissolved oxygen measurements in the LTCTF to published data for synthetic geothermal brine (Cramer 1974). The published data spans the range of temperature from 20 to $300^{\circ} \mathrm{C}$, and spans the range of oxygen partial pressures from 1 to 30 psi. Note that the partial pressure of oxygen in the atmosphere is about 3 psi. The points representing measurements from the LTCTF tanks are superimposed upon the published data. Clearly, the SDW, SCW, and SAW appear to be saturated (4 to $10 \mathrm{ppm}$ dissolved oxygen).

\subsection{LOCALIZED CORROSION}

The hydrolysis of dissolved metal in crevices can lead to the accumulation of $\mathrm{H}^{+}$and the corresponding suppression of $\mathrm{pH}$. For example, $\mathrm{pH}<2$ has been observed in crevices made of stainless steel, as discussed by Sedriks (1996). Such low $\mathrm{pH}$ can exacerbate any problems due to hydrogen induced cracking ( $\mathrm{HIC}$ ). While experimental determinations of the crevice $\mathrm{pH}$ have been made in the case of stainless steels, work for titanium-based alloys must still be done.

If the threshold potential for localized attack is exceeded, a corrosion rate representative of localized corrosion (LC) must be assumed. Unfortunately, due to the outstanding corrosion resistance of $\mathrm{Ti}$ Gr 7 , relatively little data exists for such localized corrosion under plausible conditions. From the reviewed literature (Gdowski 1997 Table 15.1), a crevice corrosion depth of 250 microns was observed in a crevice formed from Ti-0.2\% Pd and PTFE after a 582 day exposure in deaerated brine at $90^{\circ} \mathrm{C}(157$ microns per year). In a metal-metal crevice, a crevice corrosion depth of 70 microns was observed in a crevice formed from Ti-0.2\%Pd after 489 days (52 microns per year). Since these rates are less than the maximum rates represented by Equation 6-19, other more severe values should be considered in the event of passive film breakdown (Gdowski 1997 Appendix A), which are shown in Table 6-15.

Table 6-15. Assumed Distribution of Localized Corrosion Rates for $\mathrm{Ti} \mathrm{Gr} 7$

\begin{tabular}{|l|l|l|}
\hline $\begin{array}{l}\text { Percentile } \\
(\%)\end{array}$ & $\begin{array}{l}\text { Localized Corrosion Rate } \\
\text { (microns per year) }\end{array}$ & Conditions \\
\hline $0^{\text {th }}$ & 490 & $19 \% \mathrm{HCl}+4 \% \mathrm{FeCl}_{3}+4 \% \mathrm{MgCl}_{2}$ at $82^{\circ} \mathrm{C}$ \\
\hline $100^{\text {in }}$ & 1120 & Boiling $3: 1$ Aqua Regia \\
\hline
\end{tabular}

\subsection{GAMMA RADIOI YSIS}

As discussed in the companion AMR on general and localized corrosion of the WPOB, ambienttemperature cyclic polarization studies have been performed with $316 \mathrm{~L}$ samples in $0.018 \mathrm{M}$ $\mathrm{NaCl}$ solution during exposure to $3.5 \mathrm{Mrad} \mathrm{h}^{-1}$ gamma radiation (Glass 1986). This investigator found that the corrosion current shifted in the anodic direction by approximately $200 \mathrm{mV}$, with 
very little increase in the corresponding corrosion current density. However, the separation between the corrosion potential and the threshold for localized attack decreased slightly. This shift in corrosion potential was shown to be due to the formation of hydrogen peroxide. This finding was subsequently confirmed by others (Kim 1999). In this case, ambient-temperature cyclic polarization of 316 stainless steel in acidic $(\mathrm{pH} \sim 2) 1.5 \mathrm{M} \mathrm{NaCl}$ during exposure to 0.15 $\mathrm{Mrad} \mathrm{h}^{-1}$ gamma radiation showed a $100 \mathrm{mV}$ anodic shift in the corrosion potential, with very little effect on the corrosion current. While the $E_{\text {corr }}$ shift for Ti Gr 7 will probably be somewhat different than that of $316 \mathrm{~L}$, it is doubtful that the shift will ever be sufficient for $E_{\text {corr }}$ to exceed $E_{\text {critical. }}$. Thus, even in the presence of gamma radiolysis, general corrosion would be expected.

\subsection{MICROBIAL INFLUENCED CORROSION}

It has been observed that titanium based alloys are very resistant to Microbial Influenced Corrosion (MIC). Furthermore, it is believed that microbial growth in the repository will be limited by the availability of nutrients. Ultimately, the impact of MIC will be accounted by adjusting $E_{\text {corr }}, E_{\text {critical }}, \mathrm{pH}$, and the sulfide concentration. The possible acceleration of abiotic corrosion processes by microbial growth has also been a concern. Bacteria and fungi alter local environment in biofilm. For example, $\mathrm{H}^{+}$is known to be generated by bacterial isolates from Yucca Mountain. Any lowering of $\mathrm{pH}$ could tend to exacerbate hydrogen induced cracking. Furthermore, thiobaccilus ferrooxidans oxidize $\mathrm{Fe}^{2+}$, while geobacter metallireducens reduce $\mathrm{Fe}^{3+}$. Other microbes can reduce $\mathrm{SO}_{4}{ }^{2-}$ and produce $\mathrm{S}^{2-}$. In the future, we hope to calculate concentration transients in biofilms with a relatively simple bioreactor model.

\subsection{SUMMARY OF MODEL}

The model for the general and localized corrosion of Ti Gr 7 is summarized in Figure 6-17. The threshold $\mathrm{RH}$ is first used to determine whether or not dry oxidation (DOX) will take place. If dry oxidation is determined to occur, the parabolic growth law represented by Equations $6-5$ and 6-7 is then used to calculate the corrosion rate as a function of temperature. If the threshold $\mathrm{RH}$ is exceeded, HAC will occur in the absence of dripping water, and aqueous phase corrosion will occur in the presence of dripping water. If aqueous phase corrosion is assumed to occur, the corrosion and critical potentials are used to determine whether the mode of attack is general or localized. The correlation of data represented by Equation 6-11 and Table 6-1 are used as the basis for estimating these potentials at the $50^{\text {th }}$ percentile. Since the material specifications will be based partly on the measured corrosion and critical potentials, it will be assumed that these potentials will be uniformly distributed about the $50^{\text {th }}$ percentile values ciztermined from the correlation. For example, the $0^{\text {th }}$ and $100^{\text {th }}$ percentile values of $E_{\text {corr }}$ will be assumed to be at $E_{\text {corr }}\left(50^{\text {th }}\right.$ percentile $) \pm 325 \mathrm{mV}$. This acceptable margin was determined by splitting the differences shown in Table 6-2. Similarly, the $0^{\text {th }}$ and $100^{\text {th }}$ percentile values of $E_{\text {critical }}$ will be assumed to be at $E_{\text {critical }}\left(50^{\text {th }}\right.$ percentile $) \pm 325 \mathrm{mV}$. Material falling outside of these specified ranges will not be accepted. If the comparison of $E_{c o r r}$ to $E_{\text {critical }}$ indicates general corrosion, the distribution of rates determined from the LTCTF will be used as the basis of the general corrosion rate. 


\section{CHECK COPY}

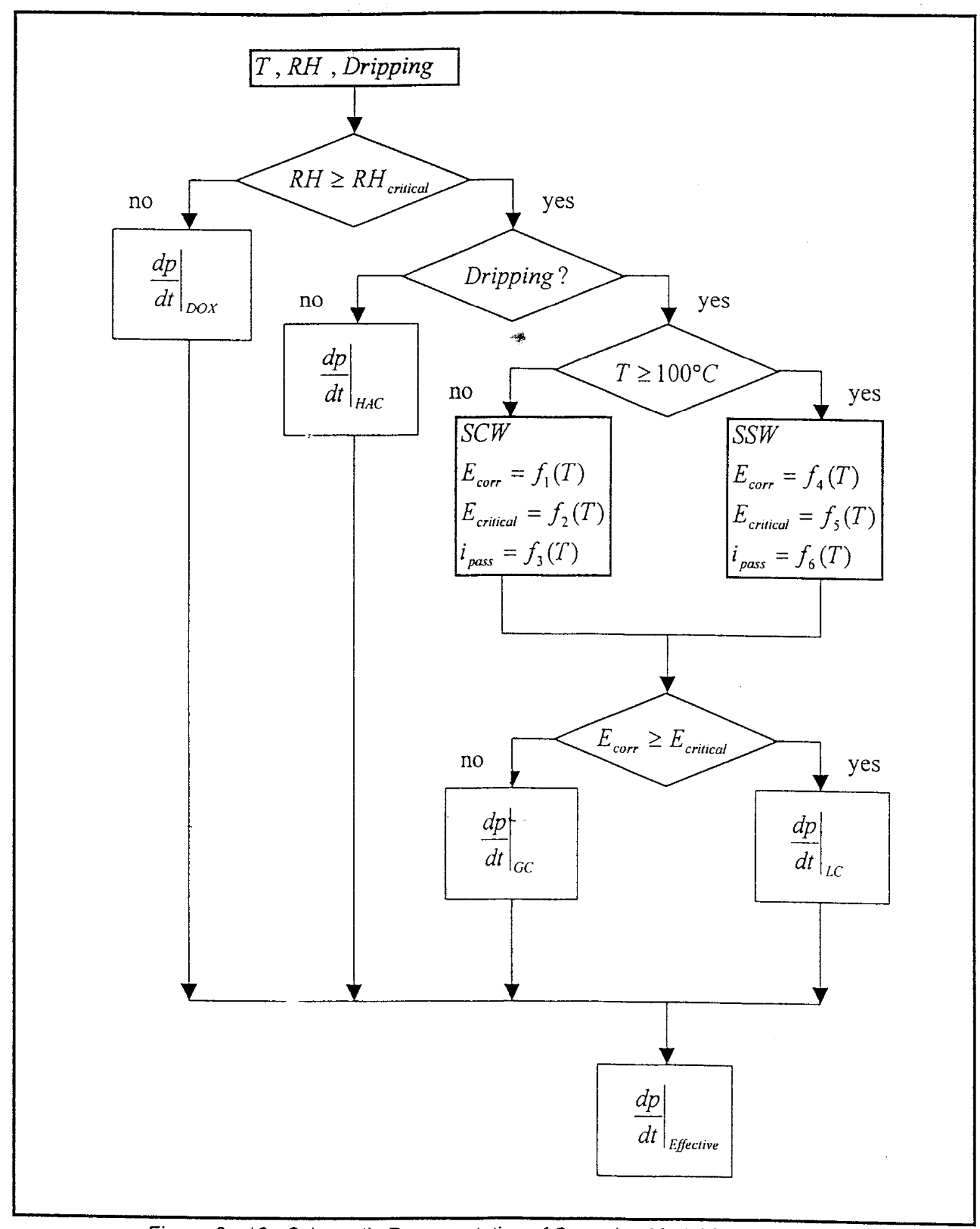

Figure 6 - 16. Schematic Representation of Corrosion Model for Drip Shield. 


\section{CHECK COPY}

\section{CONCLUSIONS}

Ti Gr 7 is an extremely corrosion resistant material, with a very stable passive film. Based upon exposures in the LTCTF, it has been determined that the general corrosion and oxidation rates of Ti Gr 7 are essentially below the level of detection. In any event, over the 10,000 year life of the repository, general corrosion and oxidation should not be life limiting. The large separation between measured corrosion and threshold potentials indicate that localized breakdown of the passive film is unlikely under plausible conditions, even in $\mathrm{SSW}$ at $120^{\circ} \mathrm{C}$. In the future, the $\mathrm{pH}$ and current in crevices formed from Ti Gr 7 should be determined experimentally.

With exposures of two years, no significant evidence of crevice corrosion has been observed with Ti Gr 16 in SDW, SCW, and SAW at temperatures up to $90^{\circ} \mathrm{C}$, though many of the samples have a beautiful green patina. An abstracted model has been presented, with parameters determined experimentally, that should enable performance assessment to account for the general and localized corrosion of this material. A feature of this model is the use of the materials specification to limit the range of corrosion and threshold potentials, thereby making sure that substandard materials prone to localized attack are avoided. 


\section{CHECK COPY}

\section{REFERENCES}

American Socieity for Testing and Materials (ASTM) 1989. "Standard Reference Test Method for Making Potentiostatic and Potentiodynamic Anodic Polarization Measurements," Designation G 5-87, 1989 Annual Book of ASTM Standards, Section 3, Vol. 3.02, pp. 79-85.

American Socieity for Testing and Materials (ASTM) 1989. " Calculation of Corrosion Rate," Subsection 8, "Densities for a Variety of Metals and Alloys," Appendix X1, "Standard Practice for Preparing, Cleaning, and Evaluating Corrosion Test Specimens," Designation G 1-81, 1987 Annual Book of ASTM Standards, Section 3, Vol. 3.02, pp. 89-94.

Asphahani, A. I. 1980. "Corrosion Resistance of High Performance Alloys," Materials Performance, Vol. 19, No. 12, pp. 33-43.

Bard, A. J.; and Faulkner, L. R. 1980. "Liquid Junction Potentials," Section 2.3, "Potentials and Thermodynamics of Cells," Chapter 2, Electrochemical Methods, Fundamentals and Applications, John Wiley and Sons, New York, NY, 1980, Eqn. 2.3.39; p. 71, Table 2.3.2, p. 67.

Burr, I. W. 1974. "Some Continuous Probability Distributions," Chaper 6, Applied Statistical Methods, Academic Press, New York, NY, Eqn. 6.17, p. 138.

Cramer, S. D. 1974. "The Solubility of Oxygen in Geothermal Brines," Corrosion Problems in Energy Conversion and Generation, C. S. Tedman, Jr., Ed., Corrosion Division, The Electrochemical Society, Princeton, NJ, pp. 251-262.

Estill, J. C. 1998. "Long-Term Corrosion Studies, in Engineered Materials Characterization Report, Corrosion Data and Modeling," Update for Viability Assessment, R. D. McCright, Ed., Lawrence Livermore National Laboratory, UCRL-ID-119564, Vol. 3, Rev. 1.1, Section 2.2, pp. 2.2-1 through 2.2-103, Figures 2.2F-1 through 2.2F-4.

Farmer, J. C.; and McCright, R. D. 1998. "Crevice Corrosion and Pitting of High-Level Waste Containers: Integration of Deterministic and Probabilistic Models," Paper No. 160, Symposium on Corrosion in Nuclear Systems, Corrosion 98, National Association of Corrosion Engineers (NACE), Houston, TX, $24 \mathrm{p}$.

Farmer, J. C.; McCright, R. D.; Estill, J. C.; and Gordon, S. K. 1998. "Develc mment of Integrated Mechanistically-Based Degradation-Mode Models for Performance Assessment of High-Level Containers," Proceedings of the Symposium on the Scientific Basis for Nuclear Waste Management XXII, Fall Meeting of the Materials Research Society, Boston, Massachusetts.

Farmer, J. C.; Estill, J. C.; McCright, R.D., 1999. "General and Localized Corrosion of Waste Package Outer Barrier," Document Identifier Number ANL-EBS-MD-000004, Rev. 00A, United States Department of Energy, Office of Civilian Radioactive Waste Management, Management \& Operating Contractor, July, 1999. 


\section{CHECK COPY}

Gartland, P. O. 1997. "A Simple Model of Crevice Corrosion Propagation for Stainless Steels in Sea Water," Paper No. 417, Corrosion 97, National Association of Corrosion Engineers (NACE), Houston, TX, $17 \mathrm{p}$.

Gdowski, G. E. 1997. "Survey of Degradation Modes of Candidate Titanium-Base Alloys for Yucca Mountain Project Waste Package Materials," UCRL-ID-121191 Rev. 1, Lawrence Livermore National Laboratory, Livermore, CA, 61 p.

Gdowski, G. E. 1997a. "Formulation and Make-up of Simulated Dilute Water (SDW), Low Ionic Content Aqueous Solution," Yucca Mountain Project, Lawrence Livermore National Laboratory, Livermore, CA, TIP-CM-06, Revision CN TIP-CM-06-0-2, Table 1, p. 3.

Gdowski, G. E. 1997b. "Formulation and Make-up of Simulated Concentrated Water (SCW), High Ionic Content Aqueous Solution," Yucca Mountain Project, Lawrence Livermore National Laboratory, Livermore, CA, TIP-CM-07, Revision CN TIP-CM-07-0-2, Table 1, pp. 3-4.

Gdowski, G. E. 1997c. "Formulation and Make-up of Simulated Acidic Concentrated Water (SAW), High Ionic Content Aqueous Solution," Yucca Mountain Project, Lawreace Livermore National Laboratory, Livermore, CA, TIP-CM-08, Revision CN TIP-CM-08-0-2, Table 1, p. 3.

Gdowski, G. E. 1999. "Environment on the Surface of Drip Shield and Waste Package Outer Barrier," Document Identifier Number ANL-EBS-MD-000001, Rev. 00A, United States Department of Energy, Office of Civilian Radioactive Waste Management, Management \& Operating Contractor, July 15, 1999.

Glass, R. S.; Overturf, G. E.; Van Konynenburg, R. A.; and McCright, R. D. 1986. "Gamma Radiation Effects on Corrosion: I. Electrochemical Mechanisms for the Aqueous Corrosion Processes of Austenitic Stainless Steels Relevant to Nuclear Waste Disposal in Tuff," Corrosion Science, Vol. 26, No. 8, p. 577-590.

Gruss, K. A.; Cragnolino, G. A.; Dunn, D. S.; and Sridar, N. 1998. "Repassivation Potential for Localized Corrosion of Alloys 625 and C22 in Simulated Repository Environments," Paper 149, Corrosion 98, National Association of Corrosion Engineers (NACE), Houston, TX, 9 p., Table 2.

Hack, H. P. 1983. "Crevice Corrosion Behavior of Molybdenum-Containing Stainless Steel in Seawater," Materials Performance, Vol. 22, No. 6 pp. 24-30.

Horn, J. A.; Rivera, A.; and Lian, T. 1998. "MIC Evaluation and Testing for the Yucca Mountain Repository," Paper 152, Symposium on Corrosion in Nuclear Systems, Corrosion 98, National Association of Corrosion Engineers (NACE), Houston, TX, 14 p.

Jones, D. A. 1996. "Faradays Law," Section 3.1.1, "Electrochemical Kinetics of Corrosion," Chapter 3, Principles and Prevention of Corrosion, $2^{\text {nd }}$ Edition, Prentice Hall, Upper Saddle River, NJ, Equations 3 and 5, pp. 75-76.

Kim, Y- K. 1987. "Effect of Gamma Radiation on Electrochemical Behavior of $9 \mathrm{Cr}-1 \mathrm{Mo}$ 


\section{CHECK COPY}

Alloy in $\mathrm{NaCl}$ Solutions," Journal of the Corrosion Science Society of Korea, Vol. 16, No. 1, pp. 25-30. 


\section{CHECK COPY}

Walton, J. C.; Cragnolino, G. S.; and Kalandros, K. 1996. "A Numerical Model of Crevice Corrosion for Passive and Active Metals," Corrosion Science, Vol. 38, No. 1, pp. 1-18.

Weast, R. C. 1978-79. CRC Handbook of Chemistry and Physics, 59 $9^{\text {th }}$ Edition, CRC Press, Incorporated, 1978-79, p. B178.

Welsch, G.; Smialek, J. L.; Doychak, J.; Waldman, J.; and Jacobson, N. S.; "High Temperature Oxidation and Properties," Chapter 2, Oxidation and Corrosion of Intermetallic Alloys, G. Welsch, P. D. Desai, Eds., Metals Information Analysis Center, Center for Information and Numerical Data Analysis and Synthesis (CINDAS), Purdue University, 2595. Yeager Road, West Lafayette, IN, pp. 169, Fig. 25.

Xu, Y.; and Pickering, H. W. 1993. "The Initial Potential and Current Distributions of the Crevice Corrosion Process," J. Electrochemical Society, Vol. 140, No. 3, pp. 658-668. 


\section{CHECK COPY}

\section{ATTACHMENTS}

Attachments to this document are listed in Table 26 below. The 100 MB ZIP Disk includes a data inventory in the form of an Excel spreadsheet.

Table 9 - 1. List of Attachments

\begin{tabular}{|c|c|c|}
\hline $\begin{array}{c}\text { Attachment } \\
\text { Number }\end{array}$ & Description & Size \\
\hline I & $100 \mathrm{MB}$ ZIP Disk for IBM with Supporting Data & \\
\hline II & & \\
\hline III & & \\
\hline V & & \\
\hline V & & \\
\hline VI & & \\
\hline VII & & \\
\hline VIII & & \\
\hline IX & & \\
\hline$X$ & & \\
\hline
\end{tabular}

